\title{
Probability density functions of long-lived tracer observations from satellite in the subtropical barrier region: data intercomparison
}

\author{
E. Palazzi ${ }^{1}$, F. Fierli ${ }^{1}$, G. P. Stiller ${ }^{2}$, and J. Urban ${ }^{3}$ \\ ${ }^{1}$ ISAC-Institute for Atmospheric Sciences and Climate, National Research Council, Bologna, Italy \\ ${ }^{2}$ Karlsruhe Institute of Technology (KIT), Institute for Meteorology and Climate Research - Atmospheric Trace Gases and \\ Remote Sensing (IMK-ASF), Karlsruhe, Germany \\ ${ }^{3}$ Department of Earth and Space Sciences, Chalmers University of Technology, Gothenburg, Sweden
}

Received: 3 June 2011 - Published in Atmos. Chem. Phys. Discuss.: 28 June 2011

Revised: 7 October 2011 - Accepted: 21 October 2011 - Published: 26 October 2011

\begin{abstract}
Past studies have shown that a clear relationship exists between the field of a passive tracer and the Probability Distribution Function (PDF) of tracer concentrations, which can be exploited to identify the position and variability of stratospheric barriers to isentropic mixing.

In the present study, we focus on the dynamical barrier located in the subtropics. We calculate PDFs of the longlived tracers nitrous oxide $\left(\mathrm{N}_{2} \mathrm{O}\right)$ and methane $\left(\mathrm{CH}_{4}\right)$ from different satellite instruments: the Microwave Limb Sounder (MLS) on board Aura, the Michelson Interferometer for Passive Atmospheric Sounding (MIPAS) on board Envisat, the Sub-Millimetre Radiometre (SMR) on board Odin and the Halogen Occultation Experiment (HALOE) on board UARS, overall covering the time period of 1992-2009.

An analysis of the consistency among the different sets of data and their capability of identifying mixing regions and barrier-to-transport regions in the stratosphere and the subtropical barrier location is a prime aim of the present study. This is done looking at the morphological structure of the one- and two-dimensional PDFs of tracer concentrations measured by the different instruments. The latter differ in their spatial and temporal sampling and resolution, and there are some systematic differences in the determination of the subtropical barrier position that have been highlighted. However, the four satellite instruments offer an overall consistent picture of the subtropical barrier annual cycle. There is a strong seasonality consistently represented, characterized by the wintertime shift of the subtropical edge toward the summer hemisphere. However, the influence of the Quasi
\end{abstract}

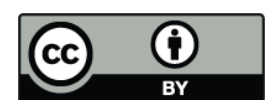

Correspondence to: E. Palazzi (e.palazzi@isac.cnr.it)
Biennial Oscillation (QBO) on isentropic transport and mixing, and by consequence, on the position of the subtropical barrier, is not equally represented in all satellite data using the methodology proposed.

\section{Introduction}

Several observational and model studies have revealed inhomogeneities in stratospheric mixing determined by regions of strong mixing separated by meridional barriers to air exchange. Strong barriers to mixing have been identified at the polar vortex edge (McIntyre and Palmer, 1984; Bowman, 1993), with the Antarctic vortex showing a more persistent barrier compared to the Arctic vortex (Allen and Nakamura, 2001; Haynes and Shuckburgh, 2000). In the mid-latitudes, mixing is generally strong due to the breaking of planetaryscale Rossby-waves propagating from the troposphere into the stratosphere when winds are westerly (and therefore primarily in winter). McIntyre and Palmer (1984) coined the term "surf-zone" for this mid-latitude stirred region. The "surf-zone" is bounded on the equatorward side by a barrier to mixing with tropical air, generating a "tropical reservoir" for tracers that are transported upward from the troposphere to the stratosphere through the tropical tropopause layer (e.g. Trepte and Hitchman, 1992). In the summer hemisphere mixing is generally weaker than during winter, since easterly winds prohibit propagation of planetary waves in the vertical. Stratospheric mixing and transport across meridional barriers play a role of primary importance in the distribution of long-lived atmospheric trace gases on isentropic surfaces (Plumb and Ko, 1992). 
A number of different diagnostics for the study of such transport mechanisms have been developed. Barriers to meridional mixing, for instance, have been revealed as steep gradients in potential vorticity (PV). Nash et al. (1996) developed a criterion based on the maximum gradient of PV in equivalent latitude to determine the edge of the polar vortex, while the model study by Struthers et al. (2009) uses the PV gradient with respect to equivalent latitude multiplied by the horizontal wind speed (called meridional impermeability, $k$ ) on a given potential temperature surface, to highlight the latitudinal structure of the meridional mixing barrier at the vortex edge, with high values of $k$ indicating regions of low meridional mixing. Both aforementioned studies use the equivalent latitude as the horizontal coordinate because it removes the effects of vortex displacement and elongation which tend to blur gradients near the vortex edge when using geographical latitude.

A recently developed quantity for atmospheric transport diagnosis is the effective diffusivity (Nakamura, 1996; Allen and Nakamura, 2001; Haynes and Shuckburgh, 2000), a modified Lagrangian mean diagnostic which is derived by transforming the tracer transport advection-diffusion equation into a diffusion-only equation by introducing coordinates based on isolines of tracer mixing ratio. Effective diffusivity is thought of as a measure of the geometric complexity of tracer contours, with tracers being based either on observations (Nakamura and Ma, 1997) or on artificial tracers advected by analyzed winds (e.g. Shuckburgh et al., 2001; Haynes and Shuckburgh, 2000). Another approach that has been used to quantify transport across meridional barriers and stratospheric mixing is the use of finite-time Lyapunov exponents (Pierrehumbert and Yang, 1993; Bowman, 1993), a derivation of the more general concept of Lyapunov exponents. The latter give a measure of the separation of two trajectories with time from initially nearby starting points and are related to the local stretching deformation of the fluid following an air parcel (that is, they are a measure of local mixing rates). The analyses presented by Garny et al. (2007), for instance, show that Lyapunov exponents appear to be a useful diagnostic of stratospheric mixing: Lyapunov exponent show regions of mixing and barriers to mixing (in the subtropics and at the polar vortex edge), and the seasonal climatology in mixing revealed by the Lyapunov exponents agrees well with the literature (Haynes and Shuckburgh, 2000; Nakamura, 1996). Another diagnostic of transport and mixing, the Lyapunov diffusivity, was presented in d'Ovidio et al. (2009). This diagnostic takes the effective diffusivity and exploits information from Lyapunov exponents and vectors to resolve the local mixing fluctuations along an equivalent latitude, in order to provide a complete latitudelongitude description of the isentropic transport and mixing structure. Shuckburgh et al. (2009) used the Lyapunov diffusivity diagnostic to investigate the seasonal and interannual variability of the transport and mixing structure of the Upper Troposphere Lower Stratosphere (UTLS) region.
Sparling (2000) has advocated the use of probability distribution functions (PDFs) of long-lived tracers (i.e. the histogram of the tracer field) to quantify mixing regions and mixing barriers. Mixing regions are associated with maxima in tracer-concentration PDFs, while barrier regions with minima. Tracer PDFs represent an alternative to the use of mean tracer gradients with the advantage that they are less sensitive to the effects of the intrusions that can shift means and they allow avoiding latitudinal smearing without necessarily relying on equivalent latitude. Sparling (2000) discussed the global statistical properties of long-lived tracers PDFs using nitrous oxide $\left(\mathrm{N}_{2} \mathrm{O}\right)$ satellite measurements and introduced the statistics of the "support" region to calculate a single characteristic latitude for the barrier regions. This approach was then applied by Neu et al. (2003) to identify the edges of the subtropical barrier and analyze their seasonal and interannual variability in the stratosphere, using $\mathrm{N}_{2} \mathrm{O}$ and $\mathrm{CH}_{4}$ satellite measurements from the Cryogenic Limb Array Etalon Spectrometer (CLAES) and the Halogen Occultation Experiment (HALOE), respectively, both aboard the Upper Atmosphere Research Satellite (UARS). One of their major results was the northern hemispheric subtropical edge shift toward the Southern Hemisphere during winter when zonal mean zonal winds are westerlies (i.e. westerly phase of the quasi-biennial oscillation, QBO) at $14.7 \mathrm{mbar}(\sim 760 \mathrm{~K})$ and $10 \mathrm{mbar}(\sim 900 \mathrm{~K})$ (no evident interannual variability linked to a QBO effect was found by Neu et al. (2003) at the lower levels $31.6 \mathrm{mbar}$ and $21.5 \mathrm{mbar}$ ).

The QBO is a reversal of the west-east winds in the tropical stratosphere occurring every 26 to 30 months (Baldwin et al., 2001), with significant extratropical consequences related to the QBO-dependent ability of the extratropical waves to propagate into and through the tropics. Through its modulation of stratospheric mixing and transport, the QBO also affects the distribution of chemical constituents like ozone, methane, and aerosols (Trepte and Hitchman, 1992; Trepte et al., 1993; Baldwin et al., 2001) and modulates the tracer gradients in the subtropics (Trepte and Hitchman, 1992). Many studies exploiting both model data and observations have shown that tracer gradients in the subtropics intensify during the easterly QBO phase. Model results by Polvani et al. (1995), for example, showed that subtropical tracer gradients are expected to be steeper in the easterly QBO phase, when there is a strong easterly shear that inhibits the propagation of Rossby waves activity into and through the tropics, than in the westerly phase. O'Sullivan and Dunkerton (1997), using $\mathrm{N}_{2} \mathrm{O}$ mixing ratios measured by the CLAES instrument, observed an increase in the winter subtropical tracer gradients during the easterly QBO phase below 10 mbar $(\sim 850 \mathrm{~K})$, since in the QBO easterly the Rossbywave activity is prevented from propagating into the tropics. Above $10 \mathrm{mbar}$, the role of the QBO is that of modulating the large scale Brewer-Dobson circulation rather than mixing. Shuckburgh et al. (2001) investigated the influence of the QBO on interannual changes in tropical-extratropical 
transport and mixing at $624 \mathrm{~K}$ (they argued that the influence is strongest at this level) over a period of six years using the equivalent length diagnostic. They found that in QBO easterlies tropospheric planetary waves are unable to propagate into the tropics but remain confined in the winter extratropics, while in QBO westerlies mixing is enhanced in the subtropics, with implications on the position of the subtropical barrier. They investigated the influence of the QBO on isentropic mixing.

In the study reported on here the method of tracer PDFs is used. The trace species considered are $\mathrm{N}_{2} \mathrm{O}$ from the Microwave Limb Sounder (MLS) instrument on board Aura, the Michelson Interferometer for Passive Atmospheric Sounding (MIPAS) on board Envisat and the Sub-Millimetre Radiometer (SMR) on board Odin, and $\mathrm{CH}_{4}$ from the HALOE/UARS instrument. Extensive comparison among MLS/Aura, MIPAS/ Envisat and Odin/SMR has been conducted in previous studies, e.g. in Urban et al. (2005), Strong et al. (2008), Lambert et al. (2007). The HALOE instrument was validated against a variety of correlative measurements (e.g. Patra et al., 2003), and through the use of remote sensors (e.g. Schoeberl et al., 2008).

We have used different satellite instruments to show to which extent the PDF diagnostics is useful to overcome possible issues related to the instrumental differences, such as the spatial and temporal sampling and resolution, and to facilitate their comparison.

The next section describes the methodology based on the use of long-lived tracer PDFs to identify transport barriers in the stratosphere and the satellite data used in this work. Section 3 discusses the morphological features of the tracer PDFs from the different satellites, and how well they can describe transport and mixing regions as reflected by troughs and peaks in the PDF. The differences and similarities among the four satellite instruments are highlighted in view of the subsequent analyses. The intercomparison among the satellite instruments in the subtropical barrier region is given in Sect. 4. Here, the systematic differences in the subtropical barrier latitude calculation among the four satellite data sets are described. The annual cycle of the subtropical barrier and the influence of the QBO on the subtropical barrier position as captured by the different instruments are also discussed in that section. The paper concludes summarizing the major findings of this study and identifying concepts and issues for future directions.

\section{Methodology and data}

\subsection{Methodology: long-lived tracer PDFs}

This paper uses a well established technique (e.g. Sparling, 2000; Palazzi and Fierli, 2010) to estimate the latitude of the subtropical boundary from the subtropical minimum in the probability distribution function (PDF) of a long-lived tracer $\chi, P(\chi)$. Given a set of observations of a tracer field $\chi, P(\chi)$ can be calculated as the fraction of observations having mixing ratios in the range from $\chi-\Delta \chi$ to $\chi+\Delta \chi$ in a given region of the atmosphere, normalized by the total area of the region. Such probability can be expressed as the definite integral:

$P(\chi-\Delta \chi<\chi<\chi+\Delta \chi)=\int_{\chi-\Delta \chi}^{\chi+\Delta \chi} f(\chi) d \chi$

where $f$ is the probability distribution function of the variable $\chi$, provided that the normalization condition is satisfied: $\int_{-\infty}^{+\infty} f(\chi) d \chi=1$ with $f(\chi) \geq 0$.

The global aspects of long-lived tracer PDFs have been widely discussed (e.g. see Fig. 3 of the paper by Sparling, 2000) and can be summarized as follows:

- there is a mapping between the spatial structure in a scatterplot of the observations of a tracer $\chi$ versus latitude and the morphology of $P(\chi)$, on a single altitude level;

- flat regions in the scatterplot map into peaks in $P(\chi)$;

- sloping regions in the scatterplot map into minima in $P(\chi)$;

- the winter hemisphere PDF has three modes: the peaks are associated to the polar vortex, tropics, and midlatitude surf-zone; the minima define the vortex edge and the subtropical boundary;

- the summer hemisphere PDF has two modes: the PDF peaks correspond to the tropics and the summer extratropics with a broader minimum between them corresponding to the subtropical barrier.

The technique used in this paper to calculate the latitude of the subtropical barrier from $P(\chi)$ relies on the application of the statistics of the "support region" introduced by Sparling (2000) and the use of a particular kind of PDF, a conditional PDF.

Referring to, e.g. Fig. 2 of the paper by Neu et al. (2003), it can be seen that, for each hemisphere, the subtropical minimum in $P(\chi)$ occurs at a precise mixing ratio value of the tracer, $\chi^{*}$, the so-called "tracer boundary" of the subtropics (the same considerations can be applied to the polar vortex edge). The "support" of the subtropical tracer boundary can be defined as the region in latitude space over which the tracer field takes on values in a neighborhood of $\chi^{*}$. From a mathematical point of view, this translates in the calculation of the PDF of the support of $\chi^{*}$, that is, the conditional PDF $P\left(\phi \mid \chi^{*}\right) . P\left(\phi \mid \chi^{*}\right)$ is the probability distribution of the latitudes of observations having mixing ratios near $\chi^{*} . P\left(\phi \mid \chi^{*}\right)$ must be calculated separately in the Northern Hemisphere (NH) and in the Southern Hemisphere (SH), because $\chi^{*}$ is not the same in the two hemispheres, and the 
most probable value of $P\left(\phi \mid \chi^{*}\right)$ identifies the subtropical barrier latitude, $\phi^{*}$ (Fig. 2d of the paper by Neu et al., 2003):

$P^{*}=\max \left[P\left(\phi \mid \chi^{*}\right)\right]$,

$\phi^{*}=\left.\phi\right|_{\left(P=P^{*}\right)}$.

In general, the two-dimensional conditional probability of the latitudes and tracer mixing ratios, $P(\phi \mid \chi)$, can be written as follows, as a derivation of the Bayes theorem:

$P(\phi \mid \chi)=\frac{P(\phi \cap \chi)}{P(\chi)}$

where $P(\phi \cap \chi)$ is the joint PDF of the latitudes and tracer concentrations, and $P(\chi)$ is the marginal probability of $\chi$ values. Another useful conditional PDF is $P(\chi \mid \phi)$, which needs the marginal PDF $P(\phi)$ to be known:

$P(\chi \mid \phi)=\frac{P(\phi \cap \chi)}{P(\phi)}$.

By integrating the function $P(\chi \mid \phi)$ over the latitudes of the Northern Hemisphere and Southern Hemisphere separately, yields the likelihood of observing a field value $\chi$ in the range $\chi-\Delta \chi$ and $\chi+\Delta \chi$, that is, the one-dimensional PDF of tracer concentrations normalized for the number of observations into each $[\phi-\Delta \phi, \phi+\Delta \phi]$ latitude bin.

It is worth pointing out that the PDF of a tracer, $P(\chi)$, is inversely proportional to the tracer latitudinal gradient, $\frac{d \chi}{d \phi}$, along an isentropic surface ( $\theta$ surface) in the stratosphere. The probability of finding the tracer concentration value $\chi$ between $\chi-\Delta \chi$ and $\chi+\Delta \chi$ within a given total surface area $S_{\text {tot }}$, in fact, should be equivalent to the probability of finding a surface area with the concentration $\chi$ between $\chi-\Delta \chi$ and $\chi+\Delta \chi$

$$
\begin{aligned}
& P(\chi-\Delta \chi<\chi<\chi+\Delta \chi)= \\
& \int_{\chi-\Delta \chi}^{\chi+\Delta \chi} P(\chi) d \chi=\frac{\int_{S_{\chi}-\Delta \chi}^{S_{\chi}+\Delta \chi} d S}{S_{\mathrm{tot}}}= \\
& \frac{1}{S_{\mathrm{tot}}} \times \int_{\chi-\Delta \chi}^{\chi+\Delta \chi} \frac{d S}{d \phi} \frac{d \phi}{d \chi} d \chi=\frac{1}{S_{\mathrm{tot}}} \times \int_{\chi-\Delta \chi}^{\chi+\Delta \chi} \frac{\frac{d S(\phi)}{d \phi}}{\frac{d \chi(\phi)}{d \phi}} d \chi
\end{aligned}
$$

where the Leibniz notation is used to express $\frac{d \phi}{d \chi}$ as $\frac{1}{\frac{d \chi}{d \phi}}$. In Eq. (5) both $\chi$ and $S$ are one-dimensional continuous and differentiable functions of the latitude, $\phi$. We define $S=$ $2 \pi R^{2}(1-\sin \phi)$ as the area north of a line of latitude $\phi$, with $R$ the Earth radius. $S_{\text {tot }}$ is the total area of one hemisphere, which is equal to $2 \pi R^{2}$. The following relationship can be derived:

$$
\frac{d \chi}{d \phi}=\cos \phi \times \frac{1}{P(\chi)}
$$

Equation (6) states that the horizontal gradient and the PDF of an atmospheric tracer form a compact relationship, provided that sampling in latitude is sufficiently uniform and dense, in order not to introduce biases and make the PDF calculation statistically significant (e.g. Sparling, 2000). Tracer PDFs are an equivalent "measure" of tracer gradients in that the minimum values of the PDFs occur at those tracer values for which the tracer gradient is maximum, indicating the location of a transport barrier. On the other hand, tracer gradients cannot be regarded as strength of the mixing barriers (Nakamura and Ma, 1997). At the NH vortex edge, for instance, tracer gradients are generally higher than they are at the $\mathrm{SH}$ vortex edge, though the Antarctic vortex shows a more persistent barrier than its Arctic counterpart (Allen and Nakamura, 2001; Haynes and Shuckburgh, 2000).

\subsection{Satellite data}

The long-lived trace constituents chosen for this study are nitrous oxide and methane: both emitted at the surface of the Earth, they have local chemical lifetimes in the stratosphere that are equivalent to or longer than the typical advection and mixing timescales, and thus they act as tracers for middle atmospheric transport processes (e.g. Brasseur and Solomon, 2005). As for any long-lived tracers, $\mathrm{N}_{2} \mathrm{O}$ and $\mathrm{CH}_{4}$ distributions are controlled by a balance between the large-scale circulation, which acts to steepen their mixing ratio isopleths, and stirring by wave activity, which acts to flatten isopleths in the stirring region but produces very strong gradients at the stirring region edges.

$\mathrm{N}_{2} \mathrm{O}$ is representative of most passive tracers in the stratosphere, with a lifetime greater than a year at $10 \mathrm{hPa}$, which increases rapidly at lower levels. It is primarily destroyed by photodissociation $(\sim 90 \%)$ and reaction with electronically excited oxygen atoms, $\mathrm{O}\left({ }^{1} \mathrm{D}\right)(\sim 10 \%)$. $\mathrm{CH}_{4}$ has a lifetime of about $3 \mathrm{yr}$ at $10 \mathrm{hPa}$, which increases rapidly below, and it is chemically destroyed above $35 \mathrm{~km}$ through reactions with $\mathrm{OH}$ and $\mathrm{O}\left({ }^{1} \mathrm{D}\right)$ producing $\mathrm{CO}$ and $\mathrm{H}_{2} \mathrm{O}$ in the middle atmosphere. There are currently four satellite instruments in orbit measuring $\mathrm{N}_{2} \mathrm{O}$. Three of these, that are used in the present study, are MLS/Aura (Waters et al., 2006; Lambert et al., 2007), MIPAS/Envisat (Fischer et al., 2008) and SMR/Odin (Murtagh et al., 2002; Urban et al., 2005); the other one is the Atmospheric Chemistry Experiment Fourier Transform Spectrometer (ACE-FTS) on SCISAT, launched in 2003 (Bernath et al., 2005). $\mathrm{CH}_{4}$ data used in this study are from the HALOE/UARS instrument (Russell et al., 1993). The main characteristics of the aforementioned satellites and instruments are outlined below and resumed in Table 1.

- The HALOE instrument was operational from September 1991 to November 2005 and used a sun occultation technique which sampled only at sunrise and sunset, yielding 15 measurements at two latitudes per day with each daily sunrise or sunset group near the same latitude on a given day, to monitor the vertical distribution of temperature and key chemical species like $\mathrm{O}_{3}, \mathrm{HCl}, \mathrm{CH}_{4}, \mathrm{H}_{2} \mathrm{O}, \mathrm{NO}, \mathrm{NO}_{2}$, and aerosol extinction (Russell et al., 1993). The instantaneous field of view 
Table 1. Basic information of the relevant sampling characteristics (nominal values) of the MLS, MIPAS, SMR, and HALOE instruments (see also the text).

\begin{tabular}{lcccc}
\hline & MLS & MIPAS & SMR & HALOE \\
\hline L2 version & v2.2 & V3O_N ${ }_{2} \mathrm{O} \_11$ & v2.1 \\
Retrieval & & V4O_N 2 O_201 & v19 \\
Temporal sampling & daily & daily & $2-3$ days week ${ }^{-1}$ & 2 latitudes day ${ }^{-1}$ \\
Horizontal sampling $(\mathrm{km})$ & 165 & $420(300)$ & 630 & 300 \\
Horizontal resolution $(\mathrm{km})$ & $300-600$ & $330-450$ & 300 & 495 \\
Vertical sampling $(\mathrm{km})$ & 2.5 & $1.5-4$ & 1.5 & 2 \\
Vertical resolution $(\mathrm{km})$ & $4-6$ & $2.5-3.7$ & $1.5-2$ & $3-5$ \\
Single profile precision & $(7-38) \%$ & $(4.5-11) \%$ & $(10-15) \%$ & $(10-15) \%$ \\
Horizontal coverage $(\mathrm{km})$ & $82^{\circ} \mathrm{S}-82^{\circ} \mathrm{N}$ & global & $82^{\circ} \mathrm{S}-82^{\circ} \mathrm{N}$ & $35^{\circ} \mathrm{S} / \mathrm{N}-80^{\circ} \mathrm{N} / \mathrm{S}$ \\
Vertical coverage $(\mathrm{km})$ & $(100-1) \mathrm{hPa}$ & $6(5.5)-70(49)$ & $12-60$ & $10-85$ \\
\hline
\end{tabular}

at the limb tangent point is approximately $2 \mathrm{~km}$ vertically by $5 \mathrm{~km}$ horizontally. The signals are highly oversampled, and after processing the effective vertical resolution is $3-5 \mathrm{~km}$. Coverage across the full range of latitudes was achieved on a time period ranging from about two to six weeks depending on the time of the year. The UARS orbit allowed coverage of the stratosphere between $35^{\circ} \mathrm{S}(\mathrm{N})$ and $80^{\circ} \mathrm{N}(\mathrm{S})$ during a northward (southward) viewing yaw period. The HALOE processing version used in this study is the third public release (V19). Version $19 \mathrm{CH}_{4}$ data are provided by the NASA Goddard Earth Sciences Data and Information Services Center (GES DISC) through the "Mirador" interface (http://mirador.gsfc.nasa.gov/).

- MLS on the NASA Aura satellite is a limb-scanning instrument, observing thermal emission at millimeter and sub-millimeter wavelengths, to measure several atmospheric chemical species $\left(\mathrm{OH}, \mathrm{HO}_{2}, \mathrm{H}_{2} \mathrm{O}, \mathrm{O}_{3}, \mathrm{HCl}\right.$, $\mathrm{ClO}, \mathrm{HOCl}, \mathrm{BrO}, \mathrm{HNO}_{3}, \mathrm{~N}_{2} \mathrm{O}, \mathrm{CO}, \mathrm{HCN}, \mathrm{CH}_{3} \mathrm{CN}$, volcanic $\mathrm{SO}_{2}$ ), cloud ice, temperature, and geopotential height. MLS scans the Earth's limb from the surface to $90 \mathrm{~km}$ with a vertical resolution of about $3 \mathrm{~km}$ in the stratosphere and the latitude coverage is nearly global (from $82^{\circ} \mathrm{S}$ to $82^{\circ} \mathrm{N}$ ), with a total of $\sim 3500$ vertical profiles per day; each profile is spaced about $1.5^{\circ}$ or $\sim 165 \mathrm{~km}$ along the orbit track (roughly 15 orbits per day). The viewing geometry of the MLS instrument allows the use of a two-dimensional approach to the retrieval problem since the limb observations from successive scans overlap significantly so that effects of lineof-sight gradients can be taken into account (Livesey and Read, 2000). Version 2.2 level $2 \mathrm{~N}_{2} \mathrm{O}$ daily vertical profiles from begin of the mission (August 2004) to
2009, available through the on-line Mirador data access, have been used.

- The MIPAS instrument was launched as part of the polar-orbiting European ENVIronmental SATellite (Envisat) on 1 March 2002 (Fischer and Oelhaf, 1996). It is a Fourier transform spectrometer providing limb spectra of atmospheric infrared emission with a spectral range extending from 685 to $2410 \mathrm{~cm}^{-1}$. It was operated with a full resolution of $0.035 \mathrm{~cm}^{-1}$ full width half maximum until operations were suspended on March 2004 due to technical problems. In January 2005 regular observations resumed, but with reduced spectral resolution which allowed more spectra to be measured during the same time interval compared to the former high spectral resolution observations. MIPAS measurements cover the whole latitude band from pole to pole with 14.3 orbits per day and about 95 limb scans per orbit in the nominal mode (altitude coverage $6-70 \mathrm{~km}$ ) and about $130 \mathrm{limb}$ scans per orbit in the UTLS mode (altitude coverage $5.5-49 \mathrm{~km}$ ). The field of view is $30 \mathrm{~km}$ in the horizontal and about $3 \mathrm{~km}$ in the vertical at the tangent points. The limb spectra of atmospheric infrared emission are analyzed to retrieve the vertical profiles of temperature, pressure and concentrations of target chemical species like, for example, $\mathrm{O}_{3}, \mathrm{H}_{2} \mathrm{O}, \mathrm{CH}_{4}$, $\mathrm{HNO}_{3}, \mathrm{~N}_{2} \mathrm{O}$ and $\mathrm{NO}_{2} . \mathrm{N}_{2} \mathrm{O}$ vertical profiles used in this work are those of version V3O_N $2 \mathrm{O}_{-} 11$ (before 2005) and version V4O_N 2 O_201 (after 2005) generated at the Institute for Meteorology and Climate Research (IMK) through the IMK-IAA data processor (von Clarmann et al., 2009a,b).

- The SMR instrument was launched as part of the Swedish mini-satellite Odin on February 2001, and it 
still operates nominally enabling to collect a long set of data. This instrument employs receivers operating in the millimetre range at around $119 \mathrm{GHz}$ and in the submillimetre range between about 486 and $581 \mathrm{GHz}$. It records emission spectra of important molecules such as, among other species, ozone and its isotopes, chlorine monoxide, nitrous oxide, nitric acid, water vapor and its isotopes and carbon monoxide. The so-called stratospheric mode measurements are performed every third day until April 2007 and every other day thereafter, time-shared with other aeronomy measurement modes. A typical stratospheric mode scan covers the altitude range from 7 to $70 \mathrm{~km}$, with a vertical sampling of about $1.5 \mathrm{~km}$ in terms of tangent altitude below $50 \mathrm{~km}$ and about $5.5 \mathrm{~km}$ above. Usually, the latitude range between $82.5^{\circ} \mathrm{S}-82.5^{\circ} \mathrm{N}$ is covered by the measurements, taken during $\sim 14-15$ orbits per day and $\sim 45$ limb scans per orbit. Retrievals are performed by two similar data processors in France and Sweden. In this study we use $\mathrm{N}_{2} \mathrm{O}$ retrievals from the level 2 processor (latest version: v2.1) of the Chalmers University of Technology (Göteborg, Sweden).

Temperature and pressure from each satellite data set have been used to interpolate tracer observations to potential temperature surfaces ( $\theta$ surfaces). Tracer data have been expressed as a function of both latitude and equivalent latitude, $\phi_{\text {eq }}$ (Nash et al., 1996), the latter being calculated from potential vorticity (PV) using the European Centre for Medium-Range Weather Forecasts (ECMWF) analyzed winds on a $1^{\circ} \times 1^{\circ}$ longitude-latitude grid and with a time resolution of $6 \mathrm{~h}$. Using equivalent latitude has the advantage of better preserving geophysical gradients around the polar vortex, by classifying air dynamically (e.g. Randel et al., 1998), while outside of polar regions there is no substantial difference between geographical latitudes and equivalent latitudes. The results presented in this paper, focused on the subtropical region, are therefore expressed in latitude.

The four different instruments make measurements in quite different ways and provide datasets with different properties. MLS measurements provide a good global coverage; the MIPAS and SMR observations not only have a global coverage but also a longer time record, while the HALOE instrument has the longest time record, but it made tropical measurements only a few times a month, compared to e.g. MLS that makes measurements about every $1.5^{\circ}$ in latitude with about fourteen passes across the equator each day. The MLS and HALOE volume mixing ratio (VMR) profiles have vertical resolutions that are similar to each other, and worse than that of MIPAS and SMR, the latter having the best vertical resolution (see Table 1). Even though the vertical resolutions of the satellite instruments are not comparable, no further processes such as vertical smoothing of higherresolved down to lower-resolved data sets has been applied. It is worth pointing out, however, that the effect of a high vertical resolution measurement (e.g. from SMR) is in part that of increasing the single-profile noise, possibly preventing the minima in the PDFs to be clearly identified in some circumstances. Our choice is motivated by the fact that drawing conclusions for zonal monthly averages rather than single profiles, as it is done in the present paper, drastically reduces noise.

As an example, Fig. 1 shows the latitude-time section of the MLS (top left), MIPAS (top right), and SMR (bottom left) $\mathrm{N}_{2} \mathrm{O}$ VMR concentrations and of the HALOE $\mathrm{CH}_{4}$ VMR concentrations (bottom right) at $600 \mathrm{~K}(\sim 30 \mathrm{hPa})$. In order to facilitate comparison among the data sets, the same time axis has been used in the plots, though the HALOE data set extends backward till 1992 (not shown). Black rhombus (crosses) superimposed to each plot indicate the subtropical barrier position, $\phi^{*}$, calculated from the tracer PDF minima (tracer meridional gradient maxima) on a seasonal basis (DJF: December-February, MAM: March-May, JJA: JuneAugust, SON: September-November). The figure shows that the regions in the subtropics where the strongest meridional variations in $\mathrm{N}_{2} \mathrm{O}$ or $\mathrm{CH}_{4}$ mixing ratio concentrations are found are collocated with the position of the subtropical barrier. In this study, the latter is derived from the minimum value of the tracer PDFs: therefore, Fig. 1 shows graphically what is expressed in Eq. (6). Focusing on the latitude range $\left[40^{\circ} \mathrm{S}-40^{\circ} \mathrm{N}\right]$, it is apparent from Fig. 1 already before any further analysis is presented, that there is a back and forth shifting of the tropical maximum region in $\mathrm{N}_{2} \mathrm{O}$ or $\mathrm{CH}_{4}$ (seen in all sensors data), and that the subtropical barriers follow the same latitudinal shifting. Superimposed to this clear annual periodicity, the tracer time series shown in Fig. 1 are also characterized by a periodicity of approximately two-years that is reflected in the position of the subtropical barrier. This modulation of subtropical tracer gradients is ascribed to the Quasi-Biennial Oscillation (QBO) in the zonal mean zonal winds, as already observed by many authors previously (e.g. O'Sullivan and Dunkerton, 1997; Gray and Russell III, 1999). The zonal mean zonal winds (in $\mathrm{m} \mathrm{s}^{-1}$ ) at $30 \mathrm{hPa}$ are overplotted in the figure as the blue lines (please note that the same $y$-axis is used for the zonal mean zonal winds and the subtropical barrier latitude). In this paper, the monthly mean zonal wind components measured at Singapore $\left(1^{\circ} \mathrm{N}\right.$, $\left.104^{\circ} \mathrm{E}\right)$ from 1992 to 2009 have been used, part of a wider database that supplies the QBO index for every year from 1987 to the present at the levels 100 (since 1997), 90, 80,70, $60,50,45,40,35,30,25,20,15,12$, and $10 \mathrm{hPa}$ available at http://www.geo.fu-berlin.de/en/met/ag/strat/produkte/qbo/.

Seasonality in the upper stratosphere is very different from the lower levels (such as $600 \mathrm{~K}$ ), showing a strong semiannual oscillation (SAO) (e.g. Gray and Pyle, 1986; Randel et al., 1998). Tracer fields and their variability, besides being different in the $\mathrm{NH}$ and $\mathrm{SH}$, also change considerably with vertical level (not shown here).

MIPAS data shown in Fig. 1 highlight that the absolute values of $\mathrm{N}_{2} \mathrm{O}$ volume mixing ratios in the tropical region 

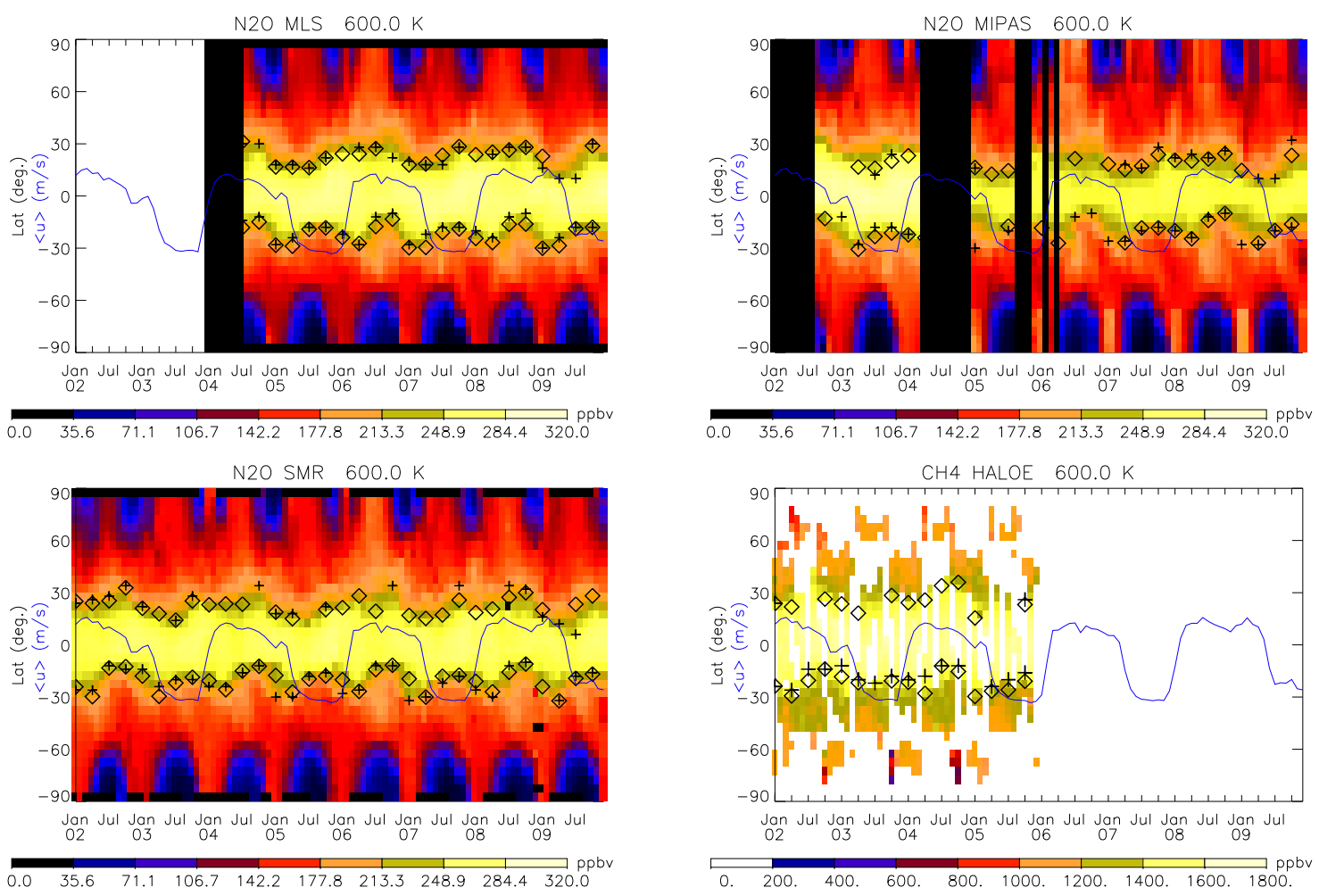

Fig. 1. Latitude-Time section of $\mathrm{N}_{2} \mathrm{O}$ volume mixing ratio (VMR) concentrations (ppb) from MLS (top left), MIPAS (top right), and SMR (bottom left) observations and of $\mathrm{CH}_{4}$ VMR concentrations (ppb) from HALOE observations (bottom right) at $600 \mathrm{~K}(\sim 30 \mathrm{hPa}$ ); rhombus (cross) symbols overplotted mark the position of the subtropical barrier calculated from the subtropical minimum of the tracer PDF (meridional gradient maximum of the tracer field). The blue line indicates the zonal mean zonal wind at $30 \mathrm{hPa}$ measured at Singapore $\left(1^{\circ} \mathrm{N}\right.$, $\left.104^{\circ} \mathrm{E}\right)$.

change (reduce) between the period 2002-2004 and after 2005 , probably as a consequence of the change from full to optimized spectral resolution which was adopted as MIPAS measurements were resumed in January 2005. However, the position of the subtropical barrier does not exhibit clear changes ascribable to the $\mathrm{N}_{2} \mathrm{O}$ bias between the highresolution and optimized-resolution phase of the MIPAS observations. This is true at the level shown in Fig. 1 (600 K), as well as at the other levels considered in our analysis (not shown here) and should be considered as an indication of the fact that the analysis of tracer PDFs allows to retrieve the subtropical barrier position without being affected by the absolute values of tracer concentrations.

In this study, $\mathrm{N}_{2} \mathrm{O}$ and $\mathrm{CH}_{4}$ probability distribution functions at different potential temperatures from $520 \mathrm{~K}$ to $1100 \mathrm{~K}$ have been analyzed on a seasonal rather than monthly basis, essentially due to the MIPAS, SMR and HALOE instruments' sparser observational horizontal sampling compared to that of the MLS instrument, prohibiting the calculation of meaningful PDFs from shorter time periods, e.g. months. The histogram bin size value is equal to two degrees for the latitudes and 1(5) ppbv for $\mathrm{N}_{2} \mathrm{O}\left(\mathrm{CH}_{4}\right)$ mixing ratio concentrations. Tracer PDFs are not evaluated if the number of data points at each potential temperature range and into each hemisphere separately is less than an arbitrary value we have set to 300 . This threshold has been chosen which allows seasons to be represented reasonably well in HALOE data, when compared to the other instruments. In fact, the HALOE orbit was drifting from year to year leading to different latitudes measured at different seasons every year, possibly introducing additional sampling uncertainties besides those due to the HALOE limited latitudinal coverage.

\section{Satellite tracer PDFs morphology}

This section focuses on the description of the four satellite data PDFs and information which can be directly derived from them, such as, for instance, their ability to distinguish mixing and barrier regions in the stratosphere with the method employed here. It will be moreover discussed to which extent the latitude of the subtropical barrier, $\phi^{*}$, can be estimated from the PDFs of each satellite data instrument.

As an example, Fig. 2 shows the one-dimensional PDFs of tracer concentrations from the four satellite instruments (MLS in black, MIPAS in blue, SMR in yellow and HALOE 

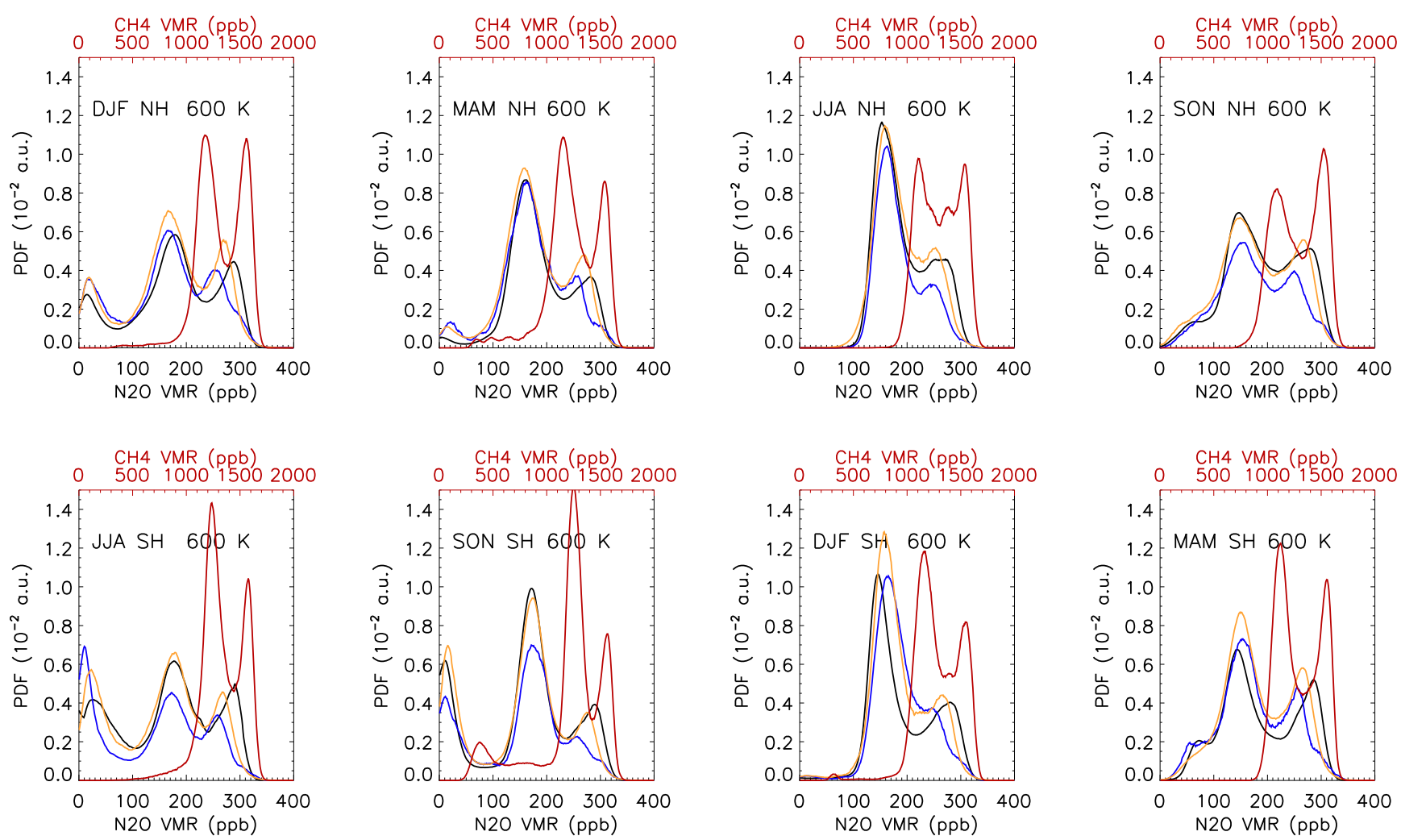

Fig. 2. Multiannual mean seasonal mean probability distribution functions of $\mathrm{N}_{2} \mathrm{O}$ (bottom $x$-axis)/ $\mathrm{CH}_{4}$ (top $x$-axis) VMR concentrations for MLS (black), MIPAS (blue), SMR (yellow), and HALOE (red) at $600 \mathrm{~K}$ ( $\sim 30 \mathrm{hPa}$ ) in the NH (upper row) and SH (lower row). Comparable seasons in the two hemispheres are lined up. The PDFs have been averaged over all of the years available from each sensor.

in red) at the potential temperature of $600 \mathrm{~K}(\sim 30 \mathrm{hPa})$ in the NH (upper row) and SH (lower row). To facilitate comparisons, the panels have been arranged such that comparable seasons in the two hemispheres are lined up. The PDFs shown in Fig. 2 are calculated as the multiannual average over the measurement years available for each sensor of the seasonal PDFs, shown as a function of the $\mathrm{N}_{2} \mathrm{O}$ VMR concentrations (bottom $x$-axis) for MLS, MIPAS and SMR, and of $\mathrm{CH}_{4} \mathrm{VMR}$ concentrations (top $x$-axis) for HALOE.

As it can be seen, $\mathrm{N}_{2} \mathrm{O}$ PDFs from MLS, MIPAS, and SMR have the same structure, as it should be for instruments having a comparable geographical coverage, and reproduce well the expected morphology of tracer PDFs during winter and summer. The winter (NH DJF and SH JJA) tracer PDFs of the three $\mathrm{N}_{2} \mathrm{O}$ sensors, in fact, are characterized by three peaks separated by two valleys, while the summer (JJA NH, DJF SH) tracer PDFs have two peaks separated by one valley. Moving from the right to the left side of the bottom $x$-axis, that is, from higher to lower $\mathrm{N}_{2} \mathrm{O}$ VMR concentrations, the regions around the three peaks in the winter PDFs correspond to the tropics, surf-zone, and the polar vortex regions, while the regions around the peaks in the summer PDFs have the tropical and extratropical $\mathrm{N}_{2} \mathrm{O}$ VMR concentrations associated. On the other hand, the HALOE instrument aboard UARS has a geographically limited coverage compared to the MLS, MIPAS and SMR measuring systems, which reflects in the morphological structure of methane PDFs shown in Fig. 2. Except for the $\mathrm{CH}_{4} \mathrm{PDF}$ during SON SH, where the polar peak can be observed centered around $400 \mathrm{ppbv}$, methane PDFs from HALOE are indeed two-modal. They are also in general well shaped, allowing for the identification of the PDF minimum value within the subtropical valley and the associated $\mathrm{CH}_{4}$ VMR concentration (i.e. the tracer boundary). The JJA NH (and, to a lesser extent, DJF SH) $\mathrm{CH}_{4}$ PDF shown in Fig. 2 represents an exception to the former statement, having a small peak feature for $\mathrm{CH}_{4}$ mixing ratio concentrations around $1400 \mathrm{ppbv}$. Though we cannot give an explanation of that, this feature arises from the JJA PDFs of the years 1996, 1998, 2000, 2002, and 2005 that contribute to the multiannual mean PDF for that season. PDFs similar to that of methane during JJA NH (Fig. 2) can prevent the calculation of the subtropical barrier latitude derived from the support theory-based algorithm, or make the error associated high. In some cases, these latitudes have been rejected. 
Despite the similarity in their shape and the overall structure, the tracer PDFs from the three $\mathrm{N}_{2} \mathrm{O}$ sensors shown in Fig. 2 differ in some aspects. There is an important difference, for instance, between the MIPAS and MLS/SMR subtropical tracer boundary value during DJF NH and JJA SH (that is, during winter). In both cases, the tracer boundary $\left(\mathrm{N}_{2} \mathrm{O}\right.$ VMR concentration corresponding to the PDF minimum value in the subtropical valley) for MIPAS (blue line) is equal to $230-240 \mathrm{ppbv}$, and it is lower than the MLS (black line) and SMR (yellow line) subtropical tracer boundary ( $\sim 260$ ppbv), denoting a possible bias between MIPAS and MLS/SMR $\mathrm{N}_{2} \mathrm{O}$ VMR concentrations in the tropical and subtropical region at this level (compare also the region of $\mathrm{N}_{2} \mathrm{O}$ tropical maximum values in MLS, MIPAS, and SMR in Fig. 1). A bias of about $10-15 \%$ between MLS and MIPAS $\mathrm{N}_{2} \mathrm{O}$ mixing ratio concentrations (MLS values greater than MIPAS values) was also documented by Lambert et al. (2007), though they used different MIPAS $\mathrm{N}_{2} \mathrm{O}$ data (the offline MIPAS $\mathrm{N}_{2} \mathrm{O}$ retrievals from algorithms developed at the University of Oxford) with respect to those we have used in the present study. The tracer boundary value bias between the three $\mathrm{N}_{2} \mathrm{O}$ sensors is also found below $600 \mathrm{~K}$ and above till $760 \mathrm{~K}$ (not shown here). At $690 \mathrm{~K}(\sim 20 \mathrm{hPa})$, the tracer boundary value bias between MIPAS and MLS/SMR is even an ubiquitous feature of the $\mathrm{NH}$ during all seasons. It is important to stress that, though not directly discussed, the general characteristics of the seasonal mean tracer PDFs from the four sensor data at $600 \mathrm{~K}$ are common to all potential temperature levels considered in this study.

Although the different instruments may be biased (in tracer volume mixing ratio concentration) relative to each other, this does not necessarily affect the PDF-estimated position of the subtropical boundaries, as we have already discussed in Sect. 2 (Fig. 1) and we will show later on.

Two-dimensional PDFs, function of the latitudes and tracer concentrations are meaningful representations of both satellite instrument characteristics (e.g. geographical coverage and latitudinal sampling) and of the ability to capture mixing and barrier-to-mixing regions in the stratosphere, at least qualitatively. Both aspects are at the same time incorporated in this kind of representation. An example of that is given in Fig. 3 for the mean June-August PDFs at $600 \mathrm{~K}$. The conditional PDFs, $P(\chi \mid \phi)$, and the joint PDFs, $P(\phi \cap \chi)$, for MLS, MIPAS, SMR, and HALOE (from left to right, respectively) are shown in the first and second row, while the lower row shows the one-dimensional PDFs (i.e. the normalized frequency distribution) of latitudes, $P(\phi)$, indicating the latitudinal sampling pattern of the four satellite instruments. It is worth remembering that, as a derivation of the Bayes theorem, the function $P(\chi \mid \phi)$ is calculated from $P(\phi \cap \chi)$ and $P(\phi)$ Eq. (4). The shape of the two-dimensional PDFs shown in Fig. 3, both $P(\chi \mid \phi)$ and $P(\phi \cap \chi)$, being a function of the latitude ( $y$-axis) and tracer concentration ( $x$-axis), is similar to, for instance, the scatter plots of CLAES $\mathrm{N}_{2} \mathrm{O}$ mixing ratio versus latitude shown by Sparling (2000) in her
Fig. 3 (panels a and b) or by Neu et al. (2003) in their Fig. 2a. There are, in fact, "slope" regions of strong tracer gradients (barrier regions) and "flat" regions of comparatively weaker tracer gradients (the tropics, surf-zone, winter polar vortex and the summer extratropics), the former being characterized by lower PDF values than the latter. All four satellite tracer PDFs reproduce well the appearance of high and low PDF regions: the two least clear situations arise in the Northern Hemisphere subtropics for the SMR $P(\chi \mid \phi)$ (third panel in the upper row) and the HALOE $P(\chi \mid \phi)$ and $P(\phi \cap \chi)$ (last column in the upper and middle row). In the first case (SMR), while $P(\chi \cap \phi)$ has a region of low PDF values in the subtropics (from about $15^{\circ}$ to $30^{\circ}$ ), the minimum in $P(\chi \mid \phi)$ is less pronounced. Looking at the SMR normalized distribution of the latitudes, $P(\phi)$, shown in the lower row of Fig. 3, it is easy to see that this difference may arise from the fact that $P(\phi)$ has a minimum just in that latitude range, and that the minimum values of $P(\phi \cap \chi)$ in the subtropics are more likely due to sampling issues (undersampling) than to transport mechanisms. In the second case (HALOE), since the sampling pattern is quite homogeneous in the $\mathrm{NH}$ tropical-subtropical region, the less noticeable minimum in both functions $P(\chi \mid \phi)$ and $P(\chi \cap \phi)$ could be ascribed to the deviation of the NH JJA one-dimensional $\mathrm{CH}_{4} \mathrm{P}(\chi)$ from the expected two-modal shape, that is to the presence of the small peak feature in the tracer PDF observed in Fig. 2.

The latitudinal extent of the tropics and of the winter surfzone is consistently reproduced by the four sensors $P(\chi \mid \phi) \mathrm{s}$ shown in the upper row of Fig. 3. The vortex and midlatitude summer extratropics reproduced by MLS, MIPAS and SMR conditional PDFs shown in Fig. 3 are also in reasonable agreement. It is worth pointing out that the difference between the winter and summer subtropical edge region width is qualitatively well captured as well by the four sensors PDFs, with a broader and less steep edge region in the summer hemisphere than in the winter hemisphere. Previous studies (Neu et al., 2003) showed that the summer edge region may occupy as much as the $60 \%$ of the area of the whole summer hemisphere at $31.6 \mathrm{mbar}(\sim 600 \mathrm{~K})$, while changes of $30-40 \%$ of the total hemispheric range of tracer values over a few degrees of latitude can occur in the winter edge region.

Conditional and joint PDFs shown in Fig. 3 give clear and quick information on the latitudinal coverage of each satellite on average during JJA, consistently with information derived from the one-dimensional tracer PDFs shown in Fig. 2. It is worth stressing that using $P(\chi \mid \phi)$ rather than $P(\phi \cap \chi)$, removes possible ambiguities in the attribution of a PDF minimum value due to undersampling, leaving dynamical mechanisms as possible explanation of the $P(\phi \mid \chi)$ morphology, but features related to the specific instrumental noise are not removed.

White symbols overplotted in the upper and middle panels of Fig. 3 mark the position of the subtropical barrier in both hemispheres, calculated from the seasonal conditional 

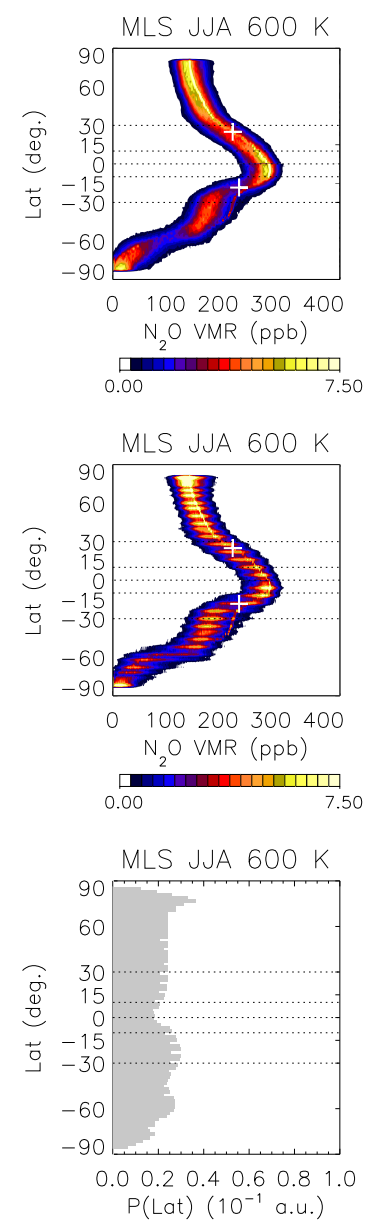
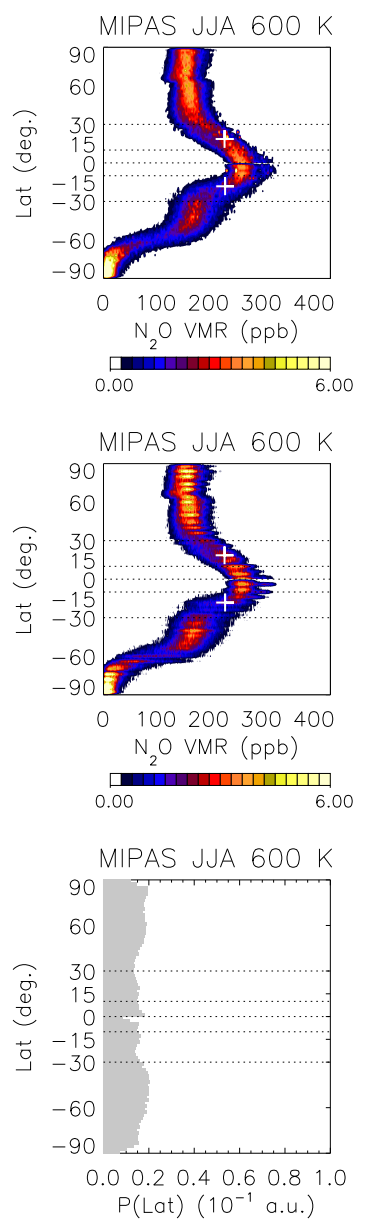
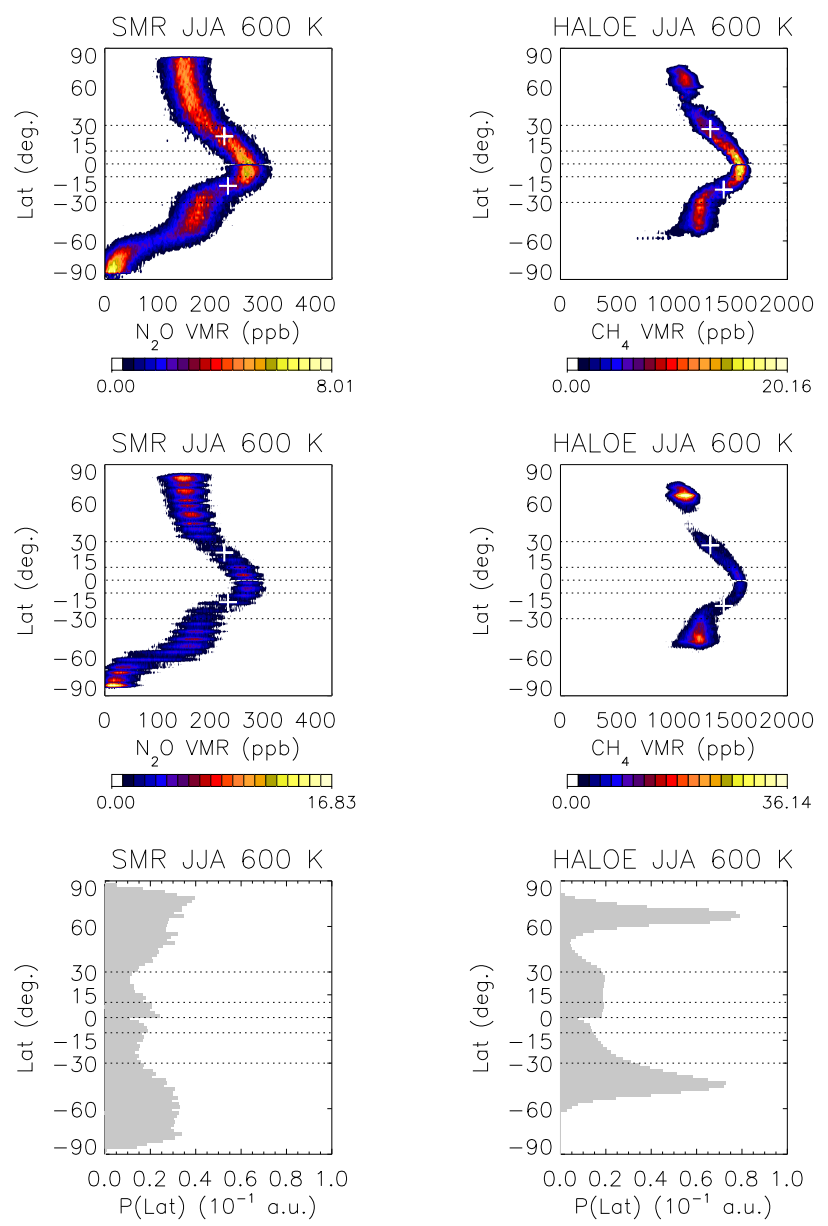

Fig. 3. Annual mean June-July-August (JJA) (upper row) conditional PDFs, $P(\chi \mid \phi)$, and (middle row) joint PDFs, $P(\chi \cap \phi)$, of tracer VMR concentrations $\left(\mathrm{N}_{2} \mathrm{O}\right.$ for MLS, MIPAS, SMR and $\mathrm{CH}_{4}$ for HALOE, from left to right) and latitudes $\phi$ at $600 \mathrm{~K}(\sim 30 \mathrm{hPa})$. The lower row shows the normalized frequency distribution of the latitudes, $P(\phi)$, on average during JJA.

PDFs through the statistics of the support region. The subtropical barrier turns out to be located at $(25 \pm 6)^{\circ},(19 \pm 3)^{\circ}$, $(21.5 \pm 5)^{\circ}$, and $(27 \pm 5)^{\circ}$ in the NH during JJA when calculated from MLS, MIPAS, SMR, and HALOE PDFs, and at $(-18.5 \pm 2)^{\circ},(-18 \pm 3)^{\circ},(-17 \pm 2)^{\circ}$, and $(-20 \pm 3)^{\circ}$ in the $\mathrm{SH}$. There is a better agreement among the four sensors in the determination of the subtropical barrier position in the Southern Hemisphere than in the Northern Hemisphere (for JJA). A smaller error is also associated to the determination of the subtropical barrier latitude in the $\mathrm{SH}$ than in the $\mathrm{NH}$, denoting a comparatively stronger variability of the JJA barrier position from year to year in the $\mathrm{NH}$ with respect to the $\mathrm{SH}$.

\section{Satellite intercomparison in the subtropical barrier region}

\subsection{Subtropical barrier latitude}

A first insight on the consistency among the subtropical barrier latitude calculated from the four satellite data PDFs is given in Fig. 4. Here, the time series of the barrier position in the NH and SH from January 2002 to November 2005 is shown; the overlapping time period of all four satellite data used in this study is from August 2004 till November 2005, as indicated by the vertical dashed lines in the figure. The horizontal grey lines mark off the region in latitude between 10 and 42 degrees in both hemispheres. The figure shows the time evolution of the subtropical barrier at four potential temperature levels, namely $600 \mathrm{~K}, 760 \mathrm{~K}, 830 \mathrm{~K}$, and $1000 \mathrm{~K}$. Black, blue, yellow and red symbols denote the MLS, MIPAS, SMR, and HALOE barrier latitude evaluation. The first impression is that there is a quite good agreement among the four sensors, especially in the Southern Hemisphere, 

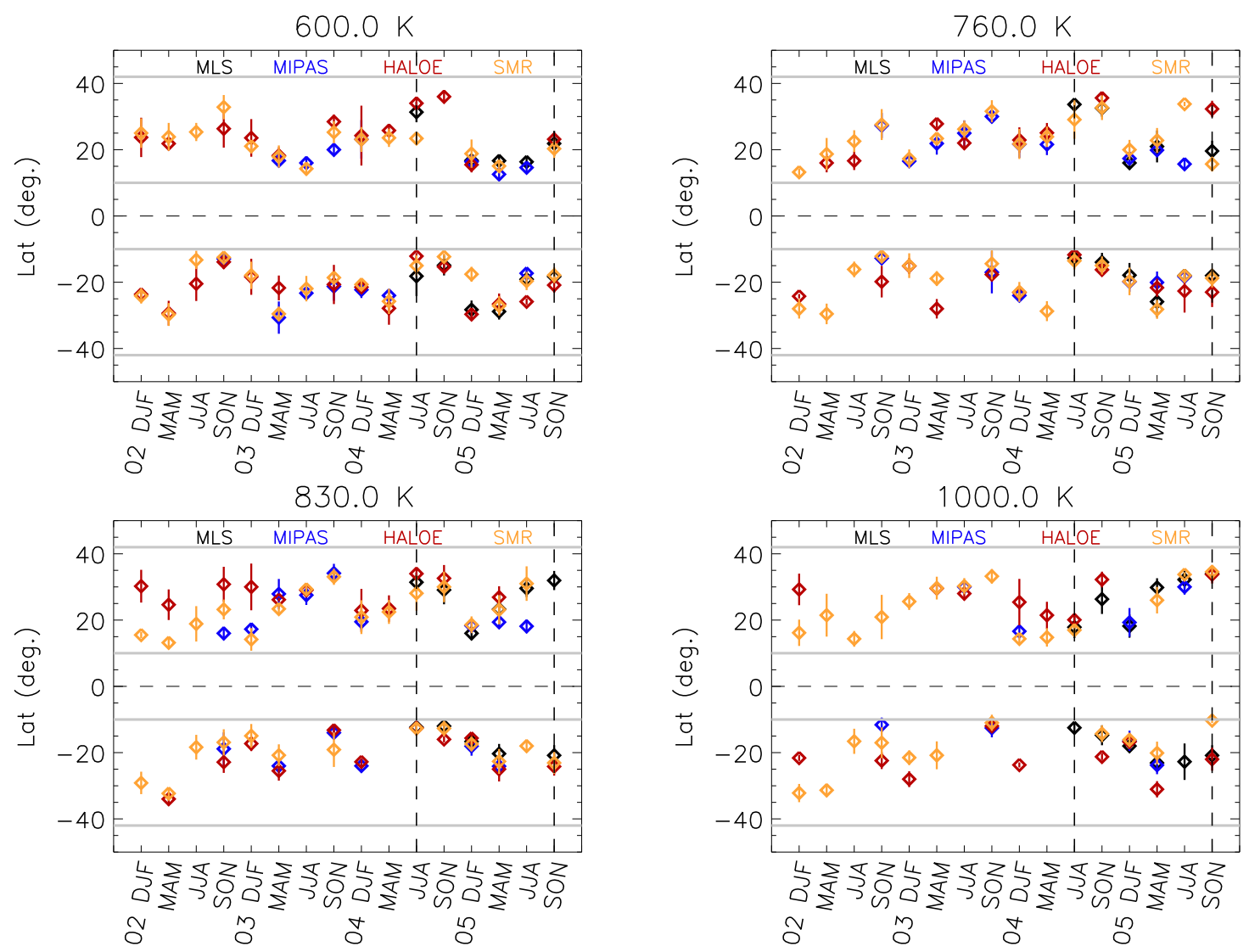

Fig. 4. Time series (seasonal data) of the subtropical barrier position from DJF 2002 to SON 2005 calculated from MLS (black), MIPAS (blue), HALOE (red), and SMR (yellow) data. Error bars are superimposed to each data point. The horizontal grey lines define the latitude region between 10 and 42 degrees in both hemispheres, while the vertical dashed lines indicate the overlapping time period of all four satellite data.

since the satellite-to-satellite comparisons generally show little scatter. However, in some cases one out of two or three satellite outputs is noticeably different from the other ones. Just focusing on the overlapping time period of all sensors data (August 2004-November 2005), the most noticeable situations of disagreement in the SH are those between SMR and MLS/HALOE at $600 \mathrm{~K}$ during DJF 2005, between MIPAS/SMR/MLS and HALOE at $600 \mathrm{~K}$ during JJA 2005, between MLS/SMR and HALOE at $1000 \mathrm{~K}$ during SON 2004, between MLS/SMR/MIPAS and HALOE at $1000 \mathrm{~K}$ during MAM 2005, and between MLS/HALOE and SMR during SON 2005. From August 2004 to November 2005 in the Northern Hemisphere, on the other hand, there is a clear discrepancy between MLS/HALOE and SMR at $600 \mathrm{~K}$ during JJA 2004, between MIPAS and SMR at $760 \mathrm{~K}$ during JJA 2005, between MLS/SMR and HALOE at $760 \mathrm{~K}$ during SON 2005, and between MLS/SMR and MIPAS at $830 \mathrm{~K}$ during JJA 2005. Nevertheless, our analysis does not indicate consistent offsets between the various instruments in different seasons, years, hemispheres, and altitudes.
In order to better quantify the inter-sensors comparison, the difference between the subtropical barrier latitude values obtained from the two sensors of each pair in their overlapping time period (seasonal data) has been evaluated. Figure 5 shows the histograms of the sensor-to-sensor barrier latitude differences grouping all altitude levels together. It is worth pointing out that the same analysis has been performed also at each level separately (not shown here), giving overall consistent results with those shown in Fig. 5, though, in some cases, the low number of data points at one single level and for one pair of sensors did not allow performing any statistically significant analysis. Histograms in Fig. 5 have been calculated using a bin size of 2 degrees latitude. The histograms statistics, that is, the number of data points used in the evaluation, the mean and standard deviation values of the distributions are presented in Table 2, and supply an indication of possible systematic differences between the sensors of each pair in the determination of the subtropical barrier latitude. Best statistics are found for the pairs MLS-MIPAS, MLS-SMR, and MIPAS-SMR, both in terms of the number of data points used in the evaluation and of 

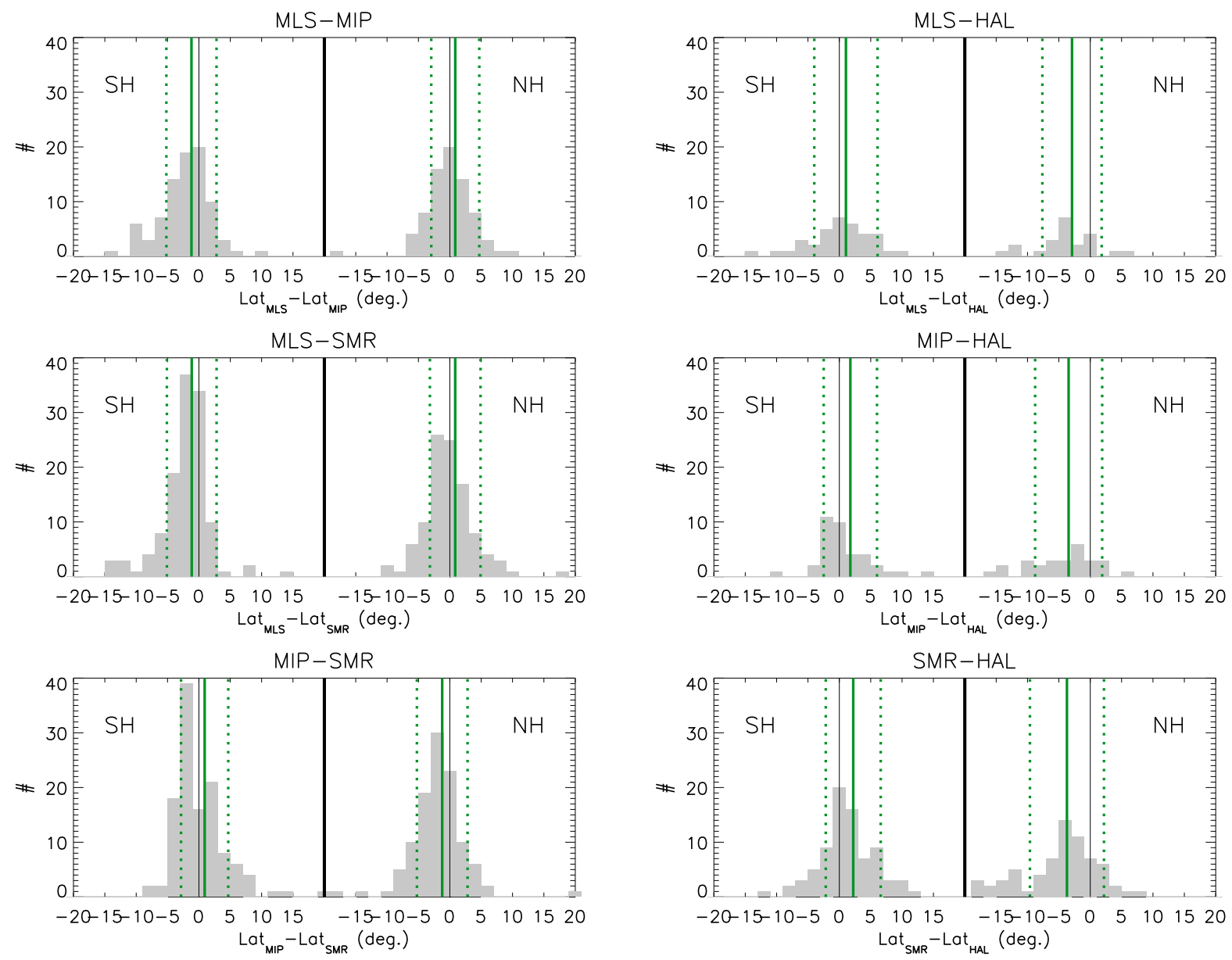

Fig. 5. Histograms of the sensor-to-sensor differences (MLS-MIPAS, MLS-SMR, MIPAS-SMR in the left column and MLS-HALOE, MIPAS-HALOE, SMR-HALOE in the right column) in the subtropical edge position. The mean and standard deviation values of the histogram distributions are shown as the solid and dashed green lines, respectively (see also Table 2).

Table 2. Mean and standard deviation values of the histogram distributions of the differences between the barrier latitude calculated from each pair of sensors shown in Fig. 5. Note that the timing of the overlap periods of the different sensor pairs is not identical.

\begin{tabular}{llcccccc}
\hline & & MLS-MIP & MLS-HAL & MLS-SMR & MIP-HAL & MIP-SMR & SMR-HAL \\
\hline \multirow{2}{*}{ \# hist } & NH & 76 & 22 & 104 & 27 & 110 & 67 \\
& SH & 85 & 36 & 123 & 37 & 118 & 79 \\
\multirow{2}{*}{ Mean $\left(^{\circ}\right)$} & NH & 0.9 & -2.9 & 0.9 & -3.4 & -1.2 & -3.7 \\
& SH & -1.2 & 1.1 & -1.1 & 1.8 & 0.9 & 2.2 \\
\multirow{2}{*}{ STD $\left(^{\circ}\right)$} & NH & 3.8 & 4.7 & 4 & 5.3 & 4 & 6 \\
& SH & 4 & 5 & 4 & 4.2 & 3.7 & 4.3 \\
\hline
\end{tabular}

the distribution properties. In these cases, in fact, the mean value of the distributions is between about zero (no difference between two sensors in the determination of the barrier latitude) and one, denoting a very good agreement among the sensors involved. The distribution of the difference between the MLS and MIPAS and the MLS and SMR latitude of the subtropical barrier in the SH and NH has a negative and positive mean value, respectively, indicating that MIPAS and SMR latitudes are on average slightly shifted equatorward with respect to MLS latitudes, in both hemispheres. The distribution of the difference between the MIPAS and SMR has a positive (negative) mean value in the $\mathrm{SH}(\mathrm{NH})$, indicating 
that the subtropical barrier latitudes evaluated from SMR are shifted poleward with respect to those evaluated from MIPAS, in both hemispheres. Concerning the pairs MLSHALOE, MIPAS-HALOE, and SMR-HALOE (right column plots in Fig. 5), our results show that in both hemispheres, the subtropical barrier latitude calculated from HALOE is always more poleward than that calculated from MLS, MIPAS and SMR. Summarizing, the pairs of sensors MLS-MIPAS, MLS-SMR, and MIPAS-SMR show a general good agreement in both hemispheres; the pair MLS-HALOE shows a good agreement only in the $\mathrm{SH}$.

\subsection{Subtropical barrier annual cycle}

This section discusses the annual cycle of the subtropical barrier position at four potential temperature levels spanning the vertical region under consideration $(600 \mathrm{~K}, 760 \mathrm{~K}, 830 \mathrm{~K}$, $1000 \mathrm{~K})$. Figure 6 shows the average over all years per sensor of the barrier latitude during each season (the multiannual mean necessarily encompasses different QBO phases); black, blue, yellow and red lines denote MLS, MIPAS, SMR, and HALOE data, respectively. It is important to observe that all sensors consistently reproduce the annual behavior of the subtropical barrier position as well as the prominent shift of the wintertime barrier toward the equator (especially in the $\mathrm{SH})$. The subtropical barrier position on average ranges from about $15^{\circ}\left(10^{\circ}\right)$ to about $35^{\circ}\left(30^{\circ}\right)$ in the $\mathrm{NH}(\mathrm{SH})$; the error bars illustrate the standard deviation of the subtropical barrier position values. There is a noticeable jump from fall to winter values, in both hemispheres. In the SH, the MAMJJA jump of the subtropical barrier position toward the equator is well captured by all sensors; at $760 \mathrm{~K}$ the jump is less marked in MIPAS data, though it is still clearly present. It is worth clarifying that the transition from fall to winter values appears as a sharp jump in Fig. 6 also because we are analyzing the annual cycle of the subtropical barrier position on a seasonal basis. As an example, Fig. 7 shows the subtropical edges as determined from the HALOE (red) and MLS (black) data on a monthly basis at the four selected potential temperature levels as shown in Fig. 6. The results for all of the HALOE years (from 1992 to 2005) and the MLS years (from 2004 to 2009) are overplotted (grey lines) to highlight the consistency of the data from year-to-year, despite significant differences in the satellite coverage (both between the two satellites and in the HALOE year-to-year coverage). In Fig. 7 we have plotted the subtropical edge position using a y-range between $90^{\circ} \mathrm{S}$ and $90^{\circ} \mathrm{N}$ in order to facilitate comparison with the Fig. 10 in Neu et al. (2003) showing the subtropical edges as determined from the HALOE data at four pressure levels (data from 1993 to 1998 in that case).

Table 3 summarizes the all sensor average of the subtropical barrier position through the year, for all $\theta$ levels considered in this study. The table emphasizes the seasonal variability in the position of the subtropical barrier in both hemispheres and the remarkable difference in the
Table 3. The subtropical barrier latitude as a function of seasons in the $\mathrm{NH}$ and $\mathrm{SH}$ at different potential temperature levels. The data are averages of MLS, MIPAS, SMR, and HALOE.

\begin{tabular}{rrrrrr}
\hline & Hem & DJF & MAM & JJA & SON \\
\hline \multirow{2}{*}{$520 \mathrm{~K}$} & $\mathrm{NH}$ & $20.4^{\circ}$ & $20.1^{\circ}$ & $23.2^{\circ}$ & \multicolumn{1}{c}{$29^{\circ}$} \\
& $\mathrm{SH}$ & $-23^{\circ}$ & $-26^{\circ}$ & $-20^{\circ}$ & $-18.9^{\circ}$ \\
\multirow{2}{*}{$600 \mathrm{~K}$} & $\mathrm{NH}$ & $20.6^{\circ}$ & $19.4^{\circ}$ & $22.9^{\circ}$ & $26.1^{\circ}$ \\
& $\mathrm{SH}$ & $-22.9^{\circ}$ & $-27.9^{\circ}$ & $-18.6^{\circ}$ & $-16.1^{\circ}$ \\
\multirow{2}{*}{$690 \mathrm{~K}$} & $\mathrm{NH}$ & $21.2^{\circ}$ & $20.7^{\circ}$ & $24.3^{\circ}$ & $22.4^{\circ}$ \\
& $\mathrm{SH}$ & $-23.1^{\circ}$ & $-26.3^{\circ}$ & $-17.2^{\circ}$ & $-16.2^{\circ}$ \\
$760 \mathrm{~K}$ & $\mathrm{NH}$ & $20.3^{\circ}$ & $21.5^{\circ}$ & $27.3^{\circ}$ & $28.1^{\circ}$ \\
& $\mathrm{SH}$ & $-20.9^{\circ}$ & $-25.6^{\circ}$ & $-15.9^{\circ}$ & $-16.4^{\circ}$ \\
$830 \mathrm{~K}$ & $\mathrm{NH}$ & $19.9^{\circ}$ & $22.1^{\circ}$ & $27.1^{\circ}$ & $30.2^{\circ}$ \\
& $\mathrm{SH}$ & $-19.6^{\circ}$ & $-25.5^{\circ}$ & $-13.2^{\circ}$ & $-17.5^{\circ}$ \\
\multirow{2}{*}{$900 \mathrm{~K}$} & $\mathrm{NH}$ & $19.1^{\circ}$ & $21.7^{\circ}$ & $27.1^{\circ}$ & $31.6^{\circ}$ \\
& $\mathrm{SH}$ & $-21.7^{\circ}$ & $-26.1^{\circ}$ & $-15.2^{\circ}$ & $-17^{\circ}$ \\
$1000 \mathrm{~K}$ & $\mathrm{NH}$ & $21.4^{\circ}$ & $21.5^{\circ}$ & $26.1^{\circ}$ & $31.4^{\circ}$ \\
& $\mathrm{SH}$ & $-22.1^{\circ}$ & $-25.2^{\circ}$ & $-17.7^{\circ}$ & $-16.4^{\circ}$ \\
\multirow{2}{*}{$1100 \mathrm{~K}$} & $\mathrm{NH}$ & $18^{\circ}$ & $29^{\circ}$ & $27.4^{\circ}$ & $32.4^{\circ}$ \\
& $\mathrm{SH}$ & $-21.4^{\circ}$ & $-22.3^{\circ}$ & $-25.8^{\circ}$ & $-16.7^{\circ}$ \\
\hline
\end{tabular}

subtropical barrier latitude between fall and winter periods, which is highlighted because of the seasonal analysis we have performed in the present study.

\subsection{Subtropical barrier position and the QBO}

The position and width of the subtropical barriers show a variation from year to year and are function of the phase of QBO (e.g. Randel et al., 1998). This section discusses to which extent information about the QBO effect on the subtropical barrier position can be extracted from the four satellite data sets analyzed using the employed methodology.

Previous studies (e.g. Shuckburgh et al., 2001; Neu et al., 2003) showed that the effect of the QBO on the subtropical barrier is that to enhance the wintertime shift of the tropicalextratropical edges toward the summer hemisphere during the QBO westerly phase. Neu et al. (2003), using $6 \mathrm{yr}$ of HALOE data, observed this effect at $14.7 \mathrm{mbar}(\sim 760 \mathrm{~K})$ and 10 mbar $(\sim 900 \mathrm{~K})$, and stated that it is difficult to see any evidence of interannual variability linked to a QBO effect at lower levels (31.6 mbar and $21.5 \mathrm{mbar}$ ). Shuckburgh et al. (2001) argued that the influence of the QBO on isentropic mixing is strongest at $624 \mathrm{~K}$ and that there is no substantial interhemispheric difference in the effect of the QBO at those altitudes.

Figure 8 shows, for each satellite instrument, the correlation between the mean position of the subtropical barrier during winter months (NH DJF and SH JJA) and the zonal mean zonal wind component at six potential temperature levels $(520 \mathrm{~K}, 600 \mathrm{~K}, 690 \mathrm{~K}, 760 \mathrm{~K}, 830 \mathrm{~K}$, and $900 \mathrm{~K})$, with positive (negative) values of the wind component denoting a QBO westerly (easterly) phase. As for Fig. 6, Fig. 8 has been obtained using the full available data set from each 

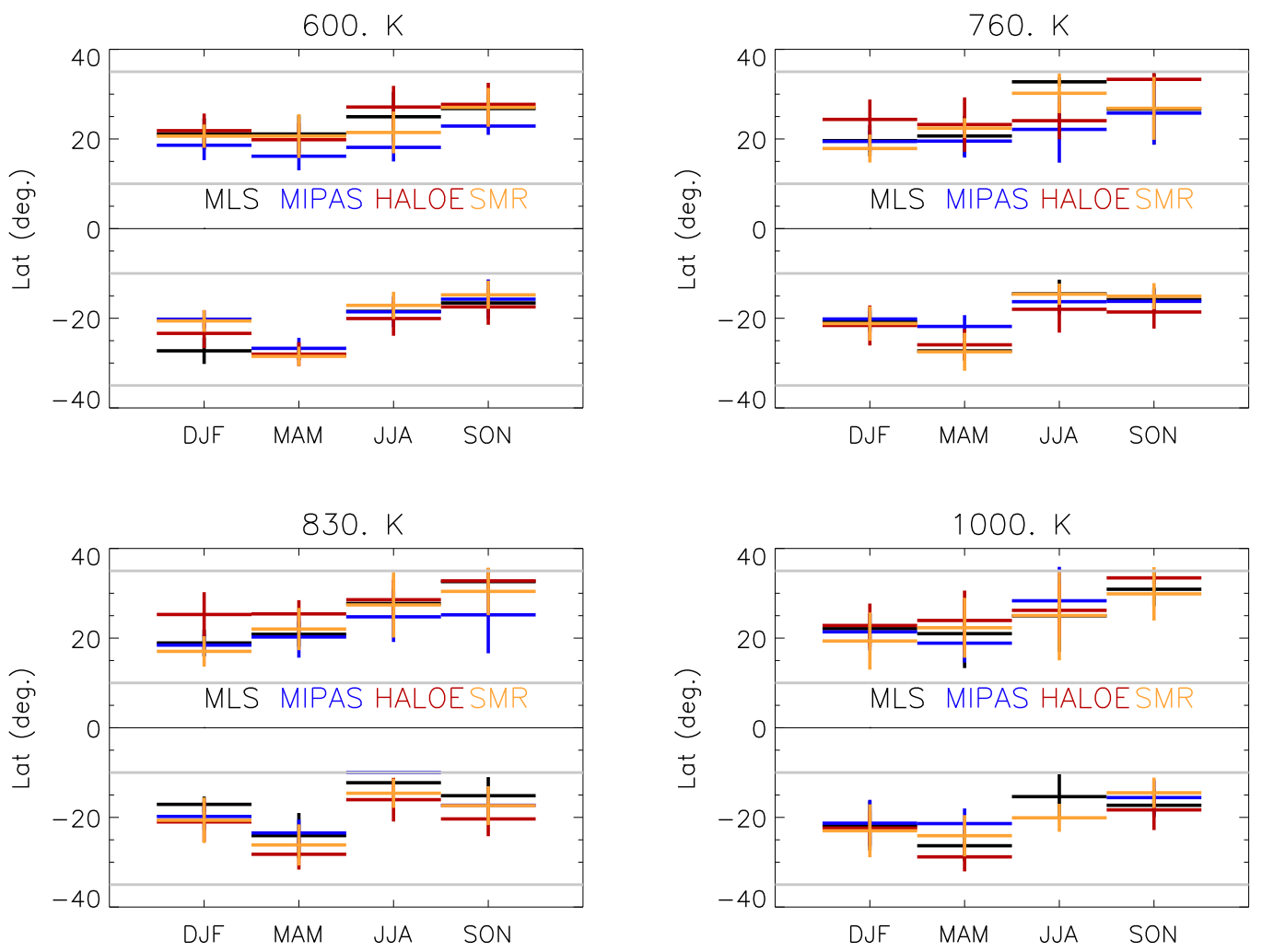

Fig. 6. Annual cycle of the subtropical barrier position (one value for each season) for the MLS (black), MIPAS (blue), SMR (yellow), and HALOE (red) instruments at $600 \mathrm{~K}, 760 \mathrm{~K}, 830 \mathrm{~K}$, and $1000 \mathrm{~K}$. The figure shows the average over all years available for each sensor, also averaged over the various QBO phases. The horizontal grey lines define the latitude region between 10 and 35 degrees in both hemispheres.

satellite instrument. The most noticeable agreement among sensors is found at $600 \mathrm{~K}$, which is near the level where the QBO effect can be considered as strongest (Shuckburgh et al., 2001): there, the QBO effect in both hemispheres is that of shifting the wintertime subtropical barrier toward the summer hemisphere when winds are westerly. Results shown in Fig. 8 for the level $600 \mathrm{~K}$ are also consistent with tracer fields shown in Fig. 1. Figure 8 shows that HALOE (red crosses) reproduces the aforementioned-wintertime effect of the QBO on the subtropical barrier position at all levels considered (not only $600 \mathrm{~K}$ ), and without significant interhemispheric differences. Previous studies using a shorter HALOE data set analyzed on pressure levels (Neu et al., 2003) found at $14.7 \mathrm{mbar}$ and $10 \mathrm{mbar}$ a similar behavior to that we observe at the roughly corresponding potential temperature levels $(760 \mathrm{~K}$ and $900 \mathrm{~K}$ ). SMR data (yellow symbols) reproduce the impact of the QBO on the subtropical barrier position consistently with HALOE in the SH and till $830 \mathrm{~K}$; MLS data (black symbols) at $520 \mathrm{~K}$ in the $\mathrm{NH}$, at $600 \mathrm{~K}$, and at $690-760 \mathrm{~K}$ in the SH; while MIPAS data (blue symbols) only from $600 \mathrm{~K}$ to $760 \mathrm{~K}$ in the $\mathrm{SH}$. The different sensors give a somewhat different picture of the QBO effect on the subtropical barrier position, with much more consistency among sensors in the $\mathrm{SH}$ than in the $\mathrm{NH}$. It can be observed, in particular, that in the $\mathrm{NH}$ at most levels, the position of the subtropical barrier calculated from the HALOE data is shifted poleward with respect to the MLS-MIPASSMR subtropical barrier position when winds are easterly. It is worth pointing out that, moreover, as shown in Fig. 1 for $600 \mathrm{~K}$, for the same time period there are much more subtropical barrier latitude values for HALOE in the SH than in the $\mathrm{NH}$, which could be a possible cause of the differences arisen when averaging data over multiple years.

Small differences in the magnitude of the changes diagnosed from $\mathrm{N}_{2} \mathrm{O}$, measured by MLS, MIPAS, and SMR, and $\mathrm{CH}_{4}$, measured by HALOE, might be expected because of their slightly different vertical and horizontal gradients. The possibility that the consistent picture given by the three $\mathrm{N}_{2} \mathrm{O}$ sensors at most levels and the somewhat different picture given by HALOE, especially in the $\mathrm{NH}$, may also result from a different behavior of the subtropical barrier in two different time periods and from the existence of trend features needs to be further investigated. It is worth remembering that the HALOE data set accounts for a very different time period extending back till 1992, while the other three data sets account for a more recent (and comparable) temporal coverage. However the HALOE subtropical barrier positions obtained for shorter time periods (e.g. 1992-1999 and 2000-2005, not 

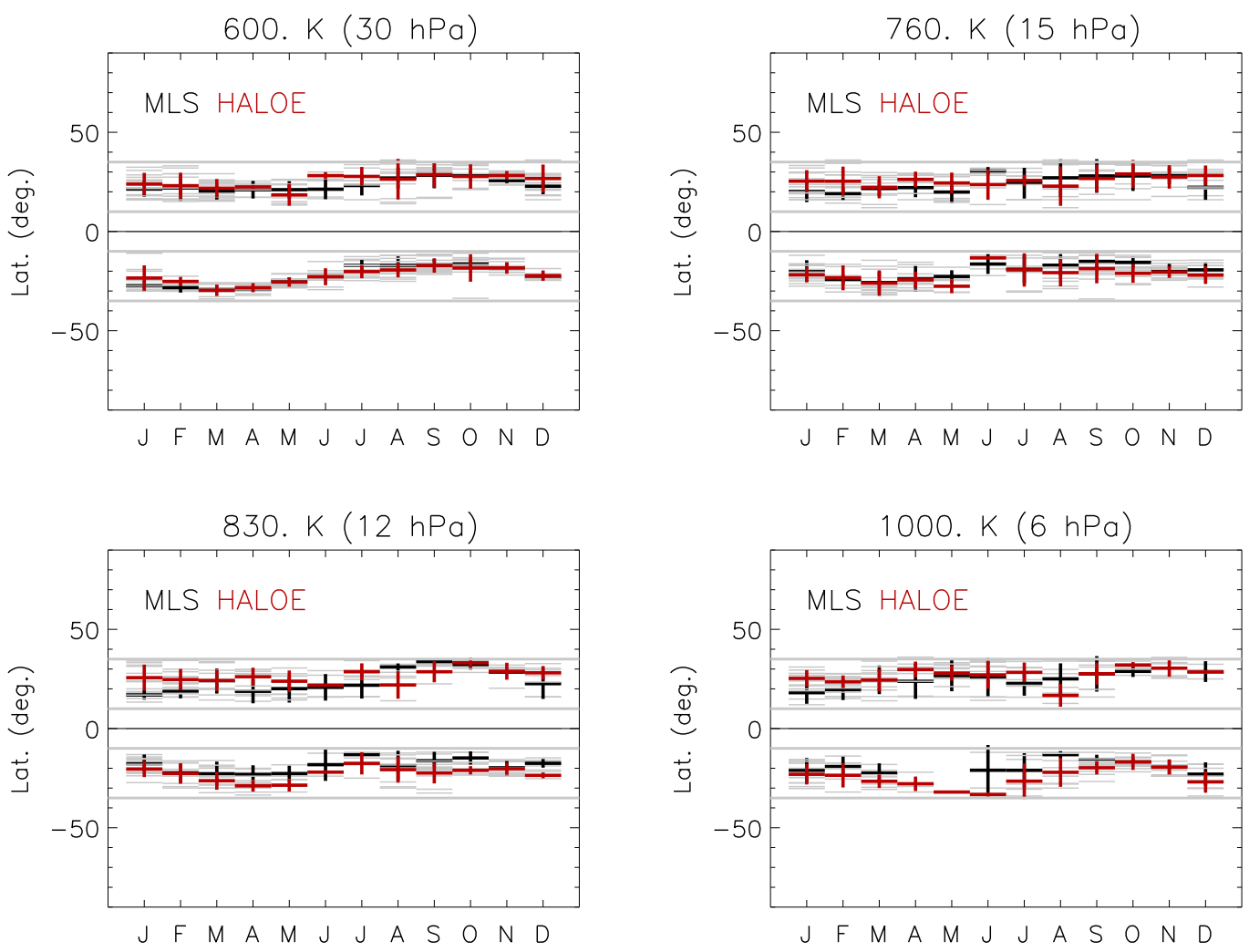

Fig. 7. Annual cycle of the subtropical barrier position (one value for each month) for the MLS (black) and HALOE (red) instruments at $600 \mathrm{~K}, 760 \mathrm{~K}, 830 \mathrm{~K}$, and $1000 \mathrm{~K}$. The figure shows the average over all years available for each sensor, also averaged over the various QBO phases. The horizontal grey lines define the latitude region between 10 and 35 degrees in both hemispheres.

shown here) do not differ substantially, though the averages are not always taken over similar and reasonably well sampled QBO phases. The temporal sampling in terms of barrier position is not the same for all sensors and levels, which should be taken into account when interpreting the differences among sensors. In Fig. 4, for instance, we have shown a reasonable agreement of all sensors at $600 \mathrm{~K}$, but sparser HALOE data and major differences at $830 \mathrm{~K}$. This is consistent with the picture obtained from Fig. 8.

In order to perform a more direct comparison between our results and those obtained from the shorter HALOE data set used by Neu et al. (2003), Fig. 9 shows the composite analysis of the subtropical barrier position through the year with respect to the phase of the equatorial QBO using the HALOE data over $14 \mathrm{yr}$ on different $\theta$ surfaces. In Fig. 9, the mean position of the subtropical barrier for every season during the westerly (easterly) QBO phase is shown in blue (red). The figure shows as the black solid (dashed) lines the position of the barriers corresponding to a change of phase from $\mathrm{W}$ to $\mathrm{E}$ (from $\mathrm{E}$ to $\mathrm{W}$ ) occurring within the three-months period of one season. It is clear from the figure that the effect of the QBO on the subtropical barrier position is an ubiquitous characteristic of all $\theta$ levels considered in this study. The vertical behavior of the subtropical barrier position calculated from the HALOE data set, for the winter period only (DJF $\mathrm{NH}$, and JJA SH) is shown in Fig. 10, with blue (red) data points indicating the position of the subtropical barrier during the westerly (easterly) QBO phase.

\section{Conclusions}

Much of what we know about stratospheric transport has been inferred from observations of long-lived tracers. The relatively recent abundance of constituent observations from satellite provides an excellent opportunity to study transport as reflected by changes in tracer distributions. Such observations, together with model studies of the atmosphere, have shown that stratospheric transport and mixing are highly inhomogeneous, with regions of strong stirring separated by barrier regions, across which there is relatively little or even nonexistent horizontal transport (Plumb, 2002).

This paper focuses on the subtropical edges that control isentropic exchanges between the tropical and extratropical stratosphere. Following the approach proposed by Sparling (2000), the methodology adopted to highlight tracer variability in the subtropical region is based on the construction of the Probability Distribution Functions (PDFs) of longlived tracer concentrations (i.e. the normalized histograms of 

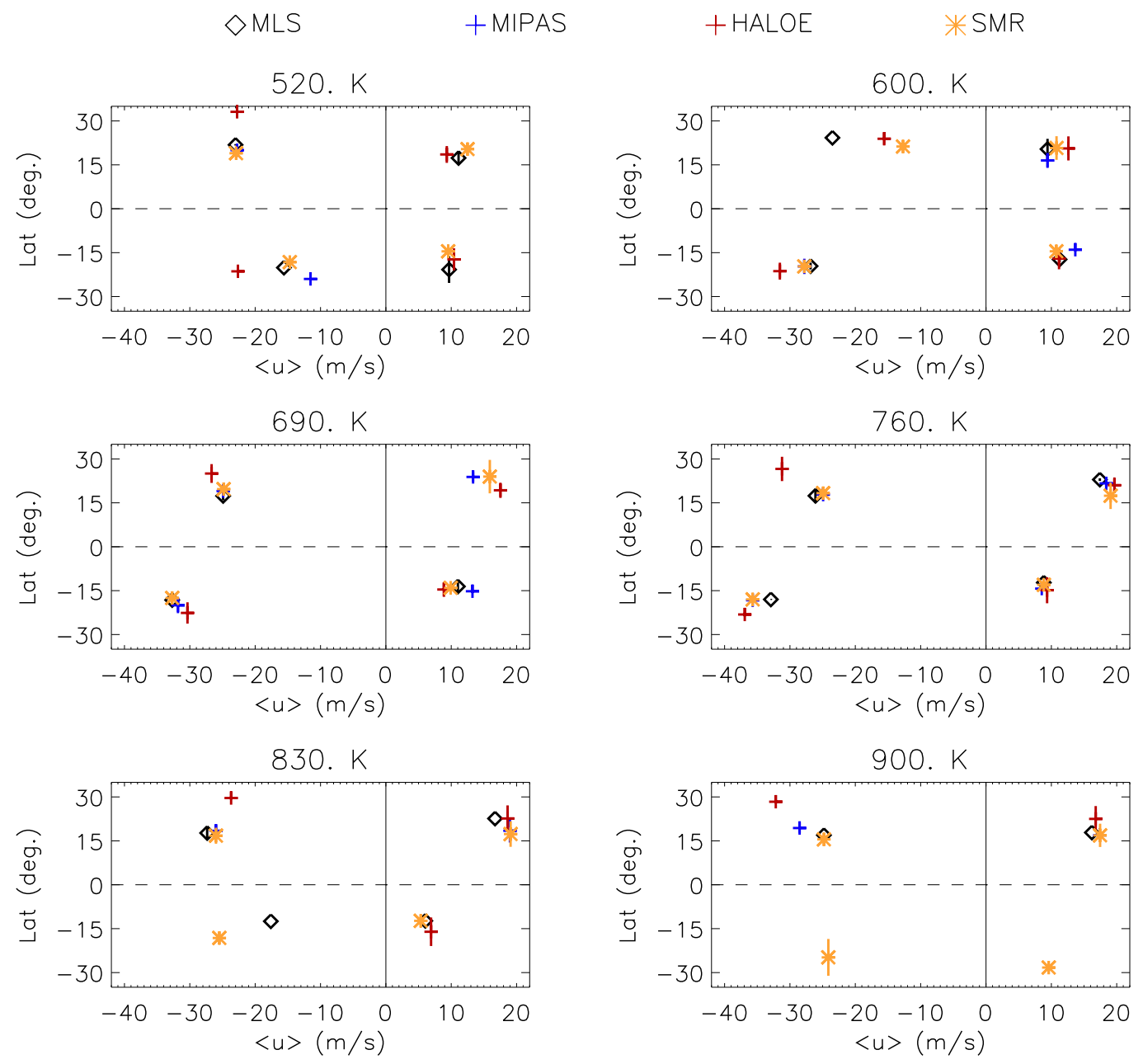

Fig. 8. Correlation between the multiannual mean winter (DJF NH, JJA SH) position of the subtropical barrier and the zonal mean zonal wind component measured at Singapore at different potential temperature levels, for the MLS (black), MIPAS (blue), SMR (yellow), and HALOE (red) instruments. Data are missing in the plots when the multiannual average at one specific level is calculated over less then 2 data points.

tracer fields). Long-lived tracers measured from satellite are used to this end. The satellite data sets consist of $\mathrm{N}_{2} \mathrm{O}$ observations from the MLS/Aura (2004-2009), MIPAS/Envisat and SMR/Odin (2002-2009) instruments and $\mathrm{CH}_{4}$ observations from the HALOE/UARS (1992-2005) instrument.

The PDF approach used in the present study is particularly indicated to perform a synthesis of large observational databases and to facilitate their comparison, because it makes the analysis to some extent independent from the absolute values of tracer concentrations. A clear example of that arising from our analysis is the fact that the position of the subtropical barrier diagnosed through the PDF analysis of MIPAS data is not affected by the change in the absolute values of MIPAS $\mathrm{N}_{2} \mathrm{O}$ volume mixing ratios between the high-resolution (2002-2004) and optimized-resolution (after 2005) phase.
Following Sparling (2000), for each satellite instrument nitrous oxide/methane PDFs in each hemisphere have been separately calculated (rather than global PDFs), in order not to combine the latitudinal variability of the Northern Hemisphere and Southern Hemisphere. Tracer PDFs have been calculated on a seasonal basis, to overcome temporal sampling inhomogeneities among the different satellite instruments and facilitate the intercomparison of the PDFrelated diagnostics applied to the different data sets. It is assessed to which extent the different characteristics of the four satellite instruments can affect the representation of the subtropical mixing barrier, in order to draw conclusions from the synopsis and merging of the data. The morphology of the tracer PDFs from the different satellite instruments has been presented, for both one-dimensional and twodimensional PDFs. For the instruments having a comparable near pole-to-pole latitudinal coverage (MLS, MIPAS, SMR), 


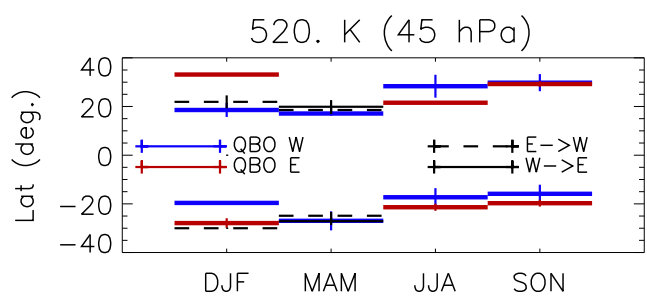

\section{HALOE}
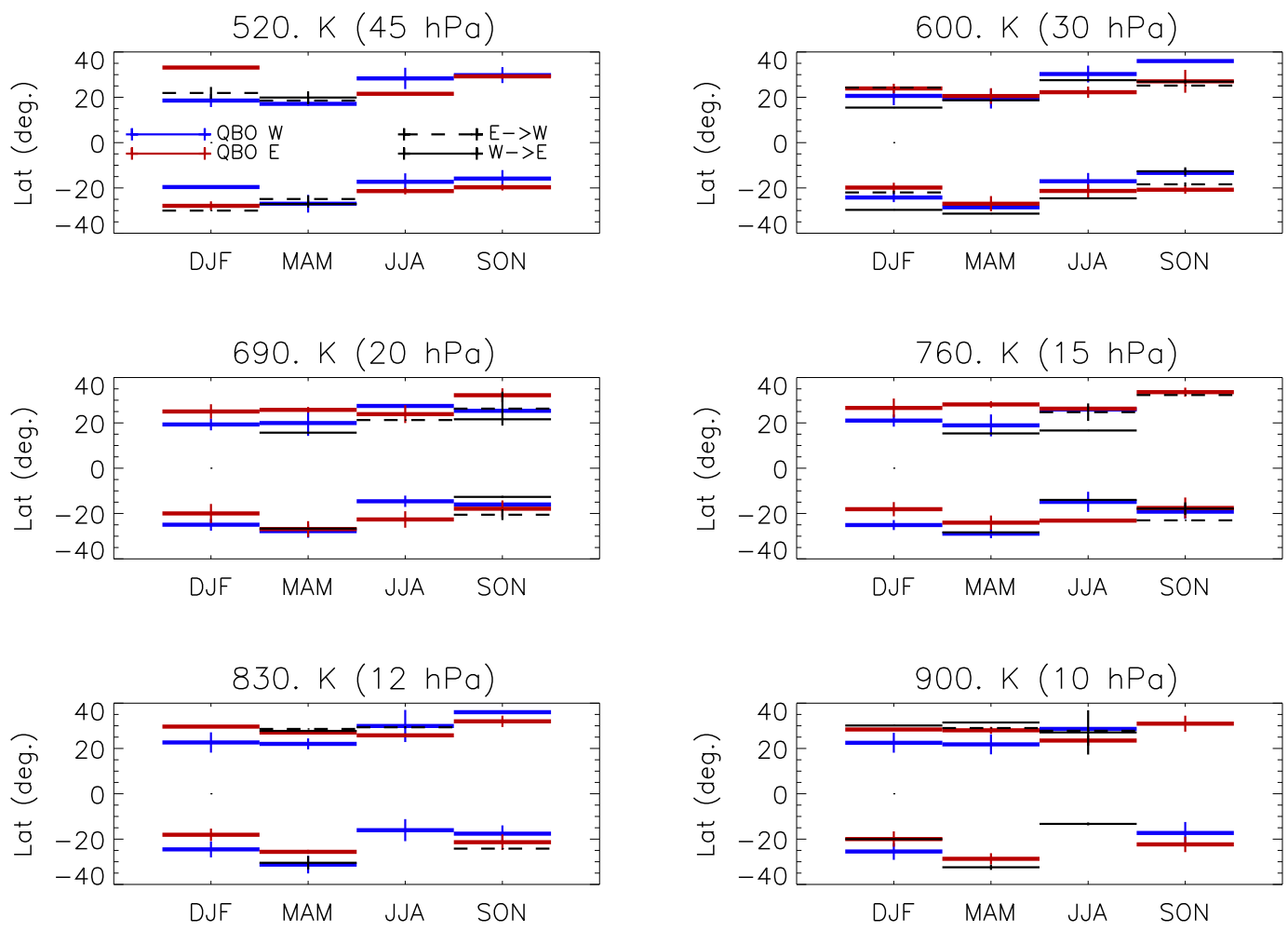

Fig. 9. QBO composite of the subtropical barrier annual cycle based on 14 yr HALOE data. Blue (red) lines denote the mean seasonal position during QBO westerly (easterly) phase. Black solid (dashed) lines denote occurrence of a transition within the three months period from westerly (easterly) to easterly (westerly) winds.

the tracer PDFs have a similar morphological structure, with two modes in the summer hemisphere and three modes in the winter hemisphere. Though being similar in their structure, the PDFs from the three $\mathrm{N}_{2} \mathrm{O}$ instruments suggest the existence of a bias in the lower stratosphere between MIPAS and $\mathrm{SMR} / \mathrm{MLS}$ in the subtropical barrier region, with lower $\mathrm{N}_{2} \mathrm{O}$ concentration for MIPAS compared to MLS and SMR, also documented in previous studies. The latitudinal coverage of the HALOE instrument is more limited (from $35^{\circ} \mathrm{S}(\mathrm{N}$ ) to $80^{\circ} \mathrm{N}(\mathrm{S})$ during a northward (southward) viewing yaw period) than the MLS, MIPAS and SMR coverage so that wintertime three-modal PDFs are less frequent in this case. The two-dimensional PDFs shown in Fig. 3 for the mean June-July-August period, have highlighted that the mixing and barrier regions in the stratosphere, represented as maximum and minimum values in the tracer PDFs, respectively, are well represented in all sensors data. The difference between the winter and summer subtropical edge region width is qualitatively well captured as well, with a broader and less steep edge region in the summer hemisphere than in the winter hemisphere.

A comparison among the four sensors of the subtropical edge position through the years (seasonal data) has been performed and presented in Fig. 4. An overall good agreement between the four satellite instruments is found, which also extends to the time period not shown in the figure. Some different values of the subtropical edge latitude, however, are found in some cases when calculated from one data set or another, probably due to an ambiguous or wrong identification of the tracer PDF minimum from which the subtropical barrier latitude is determined. Nevertheless, systematic differences among the sensors are typically less than $4^{\circ}$ (see also Table 2) during the overlapping time periods of each pair of sensors, with best agreements found between MLSMIPAS, MLS-SMR, and MIPAS-SMR, for which the overlapping time period is actually the longest. Despite the short temporal matching, MLS and HALOE also give a similar picture of the subtropical barrier position, particularly in the Southern Hemisphere.

Despite their large differences in the latitudinal coverage, temporal and spatial sampling, the instrumental characteristics and the measured chemical species, the four sensors consistently reproduce the subtropical edge annual cycle (Fig. 6) and are able to capture the most prominent features of the seasonal variability, such as the wintertime shift of the barrier position toward the summer hemisphere. The difference in the position of the subtropical barrier from fall to winter is highlighted in our analysis which is performed on a seasonal 


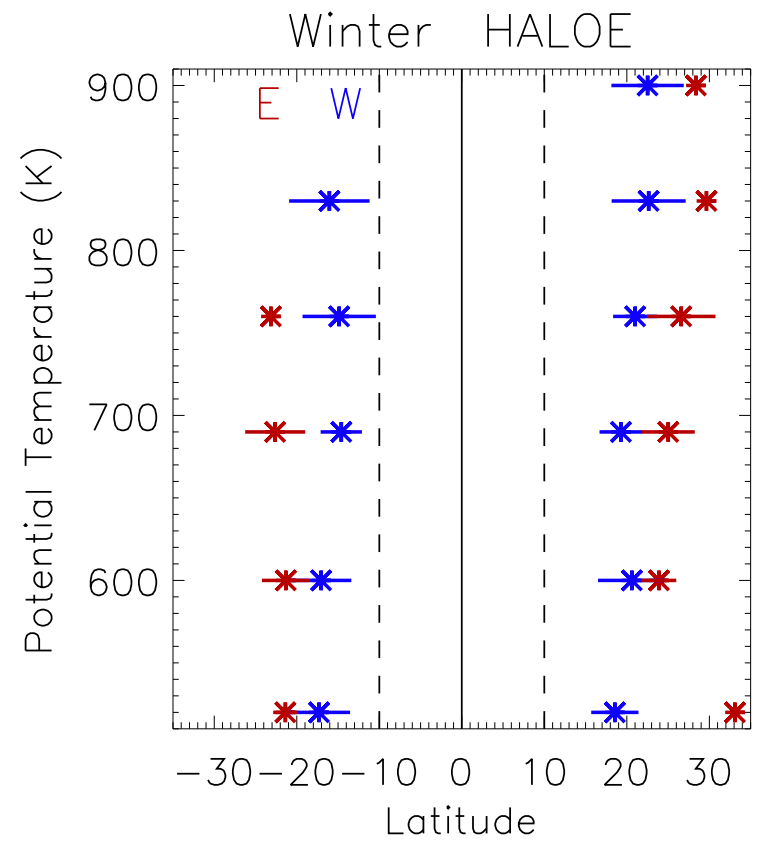

Fig. 10. Wintertime (DJF NH, JJA SH) vertical evolution of the subtropical barrier position during the Westerly (blue) and Easterly (red) QBO phase, based on the QBO composite of the HALOE data set.

basis. The transition is comparatively more smoothed, but still present, when the analysis is performed on a monthly basis. The MLS instrument allows a monthly (even daily) PDF analysis due to its measurements density and geographically unbiased sampling; the HALOE instrument, on the other hand, has a comparatively sparser sampling but can be directly compared to the analysis presented by Neu et al. (2003) that used HALOE data from 1993 to 1998 to study the variability of the subtropical edges in the stratosphere and the QBO influence.

Using the monthly mean zonal wind components measured at Singapore $\left(1^{\circ} \mathrm{N}, 104^{\circ} \mathrm{E}\right)$ from 1992 to 2009 , we have analyzed the effect of the QBO on the subtropical barrier position, and discussed to which extent such an information can be extracted from the four satellite data sets analyzed. All sensors show that an effect of the QBO on the subtropical barrier position in both hemispheres is present at $600 \mathrm{~K}$, and it manifests itself as a wintertime shift of the subtropical edge toward the summer hemisphere during the westerly phase of the QBO, in response to the enhanced stirring in the subtropics during that phase. This is consistent with the analysis performed by Shuckburgh et al. (2001) at $624 \mathrm{~K}$, using the equivalent length diagnostic calculated from nitrous oxide fields simulated in chemical transport models. The HALOE data set, which is the longest among those considered in this study (14 yr long), reproduces the same effect of the QBO as observed at $600 \mathrm{~K}$ also below and above that level, with no substantial interhemispheric differences. This has been compared with the analysis presented by Neu et al.
(2003) that used a shorter HALOE dataset (6 yr), analyzed on pressure levels rather than potential temperature surfaces. Neu et al. (2003) stated that there is evidence of some interannual variability in the seasonal behavior of the subtropical edges, which is consistent with variability in the tropical winds associated with the QBO: below $10 \mathrm{mb}$ (about $900 \mathrm{~K}$ in our analysis), there is evidence that the edges are shifted toward the Southern Hemisphere during Northern Hemisphere winter when the QBO phase is westerly. There is a substantial agreement between our HALOE analysis and the analysis presented by Neu et al. (2003) below $10 \mathrm{mb}$. The other sensors, in part due to the shorter time series (MLS), in part to the higher noise in the measured profiles (SMR, MIPAS) that makes it more difficult to detect a minimum in the tracer PDFs, do not capture the QBO effect everywhere as HALOE indeed does. The different instruments performances have been highlighted in the text; in general, the wintertime shift of the barrier position toward the equator during the westerly phase of the QBO is much more visible in the Southern than Northern Hemisphere.

To conclude, the present paper analyzes for the first time four different sets of satellite data measuring different species with a common species-independent diagnostics to supply a quantitative assessment of the subtropical barrier variability. Despite their differences and within the respective biases, MLS, MIPAS, SMR and HALOE analyzed data consistently reproduce the annual variability of the subtropical barrier within the altitude range considered in the present study $(520-1100 \mathrm{~K})$. The quasi-biennial variability is not equally reproduced by all sensor data probably due to their different temporal coverage and uneven representations of QBO westerly and easterly periods.

The combination of the four data sets allows a long time series (1992-2009) to be available for future unbiased trend analyses of the subtropical edge positions and mixing across the subtropical barrier. A better knowledge of transport mechanisms across dynamical edge regions is important for the modeling community. In the most recent Chemistry Climate Models (CCMs) (SPARC CCMVal, 2010), the inability to maintain the separation and the depth of the minimum between the tropical and midlatitude modes has been used to indicate that a model has too much tropical-extratropical mixing, which acts to homogenize tracer distributions. The PDF diagnostics used in the present paper is therefore indicated to perform direct model-measurements comparisons and process-oriented validation of CCMs, as was done, for instance, by Douglass et al. (1999), Gray and Russell III (1999), and Strahan and Douglass (2004), and as also shown in SPARC CCMVal (2010). The PDF approach, in fact, also answers to the need for synthesis of not only a large and growing database of observations of the atmosphere, but also of the outputs generated by atmospheric models. Since models cannot capture all the details of a tracer field, there is a need to perform comparisons between observations and model data that are to some extent independent from these 
details, which can be done using statistical approaches like that of tracer PDFs.

Acknowledgements. Elisa Palazzi acknowledges the European Space Agency (ESA) for supporting the project DIMITRI (Diagnostics of MIxing and TRansport in atmospheric Interfaces) in the framework of the ESA Changing Earth Science Network Initiative.

MIPAS level-1b data were provided by ESA. MLS/Aura and HALOE/UARS data were acquired as part of the activities of NASA's Science Mission Directorate, and are archived and distributed by the Goddard Earth Sciences (GES) Data and Information Services Center (DISC). Odin is a Swedish-led satellite project funded jointly by Sweden (SNSB), Canada (CSA), Finland (TEKES), France (CNES), and the third-party mission program of the European Space Agency (ESA). Authors acknowledge Stefan Lossow from the Institute for Meteorology and Climate ResearchAtmospheric Trace Gases and Remote Sensing (IMK-ASF) for his support with SMR data.

Edited by: P. Haynes

\section{References}

Allen, D. and Nakamura, N.: A seasonal climatology of effective diffusivity in the stratosphere, J. Geophys. Res., 106 (D8), 79177935, 2001.

Baldwin, M. P., Gray, L. J., Dunkerton, T. J., Hamilton, K., Haynes, P. H., Randel, W. J., Holton, J. R., Alexander, M. J., Hiorta, I., Horinouchi, T., Jones, D. B. A., Kinnersley, J. S., Marquardt, C., Sato, K., and Takahashi, M.: The quasi-biennial oscillation, J. Geophys. Res., 104, 30937-30946, 2001.

Bernath, P. F., McElroy, C. T., Abrams, M. C., Boone, C. D., Butler, M., Camy-Peyret, C., Carleer, M., Clerbaux, C., Coheur, P. F., Colin, R., DeCola, P., De Mazière, M., Drummond, J. R., Dufour, D., Evans, W. F. J., Fast, H., Fussen, D., Gilbert, K., Jennings, D. E., Llewellyn, E. J., Lowe, R. P., Mahieu, E., McConnell, J. C., McHugh, M., McLeod, S. D., Michaud, R., Midwinter, C., Nassar, R., Nichitiu, F., Nowlan, C., Rinsland, C. P., Rochon, Y. J., Rowlands, N., Semeniuk, K., Simon, P., Skelton, R., Sloan, J. J., Soucy, M. A., Strong, K., Tremblay, P., Turnbull, D., Walker, K. A., Walkty, I., Wardle, D. A., Wehrle, V., Zander, R., and Zou, J.: Atmospheric Chemistry Experiment (ACE): mission overview, Geophys. Res. Lett., 32, L15S01, doi:10.1029/2005GL022386, 2005.

Bowman, K.: Large-scale isentropic mixing properties of the Antarctic polar vortex from analyzed winds, J. Geophys. Res., 98, 23013-23027, 1993.

Brasseur, G. P. and Solomon, S.: Aeronomy of the middle atmosphere, 3rd Edn., Springer, Dordrecht, The Netherlands, 1-646, 2005.

Douglass, A. R., Prather, M. J., Hall, T. M., Strahan, S. E., Rasch, P. J., Sparling, L. C., Coy, L., and Rodriguez, J. M.: Choosing meteorological input for the global modeling initiative assessment of high-speed aircraft, J. Geophys. Res., 104, 2754527564, 1999.

d'Ovidio, F., Shuckburgh, E., and Legras, B.: Local Mixing Events in the Upper Troposphere and Lower Stratosphere, Part I: Detection with the Lyapunov Diffusivity, J. Atmos. Sci., 66, 36783694, 2009.
Fischer, H. and Oelhaf, H.: Remote sensing of vertical profiles of atmospheric trace constituents with MIPAS limb emission spectrometers, Appl. Optics, 35, 2787-2796, 1996.

Fischer, H., Birk, M., Blom, C., Carli, B., Carlotti, M., von Clarmann, T., Delbouille, L., Dudhia, A., Ehhalt, D., Endemann, M., Flaud, J. M., Gessner, R., Kleinert, A., Koopman, R., Langen, J., López-Puertas, M., Mosner, P., Nett, H., Oelhaf, H., Perron, G., Remedios, J., Ridolfi, M., Stiller, G., and Zander, R.: MIPAS: an instrument for atmospheric and climate research, Atmos. Chem. Phys., 8, 2151-2188, doi:10.5194/acp-8-2151-2008, 2008.

Garny, H., Bodeker, G. E., and Dameris, M.: Trends and variability in stratospheric mixing: 1979-2005, Atmos. Chem. Phys., 7, 5611-5624, doi:10.5194/acp-7-5611-2007, 2007.

Gray, L. J. and Pyle, J. A.: The semi-annual oscillation and equatorial tracer distributions, Q. J. Roy. Meteor. Soc., 112, 387-407, doi:10.1002/qj.49711247207, 1986.

Gray, L. and Russell III, J. M.: Interannual variability of trace gases in the subtropical winter stratosphere, J. Atmos. Sci., 56, 977993, 1999.

Haynes, P. and Shuckburgh, E.: Effective diffusivity as a diagnostic of atmospheric transport 1. Stratosphere, J. Geophys. Res., 105, 22777-22794, 2000.

Lambert, A., Read, W. G., Livesey, N. J., Santee, M. L., Manney, G. L., Froidevaux, L., Wu, D. L., Schwartz, M. J., Pumphrey, H. C., Jimenez, C., Nedoluha, G. E., Cofield, R. E., Cuddy, D. T., Daffer, W. H., Drouin, B. J., Fuller, R. A., Jarnot, R. F., Knosp, B. W., Pickett, H. M., Perun, V. S., Snyder, W. V., Stek, P. C., Thurstans, R. P., Wagner, P. A., Waters, J. W., Jucks, K. W., Toon, G. C., Stachnik, R. A., Bernath, P. F., Boone, C. D., Walker, K. A., Urban, J., Murtagh, D., Elkins, J. W., and Atlas, E.: Validation of the Aura Microwave Limb Sounder middle atmosphere water vapor and nitrous oxide measurements, J. Geophys. Res., 112, D24S36, doi:10.1029/2007JD008724, 2007.

Livesey, N. J. and Read, W. G.: Direct retrieval of line-of-sight atmospheric structure from limb sounding observations, Geophys. Res. Lett., 27, 891-894, 2000.

McIntyre, M. E. and Palmer, T. N.: The "surf zone" in the stratosphere, J. Atmos. Terr. Phys., 46, 825-849, 1984.

Murtagh, D., Frisk, U., Merino, F., Ridal, M., Jonsson, A., Stegman, J., Witt, G., Eriksson, P., Jimenez, C., Megie, G., de la Noe, J., Ricaud, P., Baron, P., Pardo, J. R., Hauchcorne, A., Llewellyn, E. J., Degenstein, D. A., Gattinger, R. L., Lloyd, N. D., Evans, W. F. J., McDade, I. C., Haley, C. S., Sioris, C., von Savigny, C., Solheim, B. H., McConnell, J. C., Strong, K., Richardson, E. H., Leppelmeier, G. W., Kyrola, E., Auvinen, H., and Oikarinen, L.: An overview of the Odin atmospheric mission, Can. J. Phys., 80, 309-319, 2002.

Nakamura, N.: Two-dimensional mixing, edge formation, and permeability diagnosed in area coordinates, J. Atmos, Sci., 53, 1524-1537, 1996.

Nakamura, N. and Ma, J.: Modified Lagrangian mean diagnostics of the stratospheric polar vortices 2 . Nitrous oxide and seasonal barrier migration in the cryogenic limb array etalon spectrometer and SKYHI general circulation model, J. Geophys. Res., 102 (D22), 25721-25735, 1997.

Nash, E., Newman, P., Rosenfield, J., and Schoeberl, M.: An objective determination of the polar vortex using Ertel's potential vorticity, J. Geophys. Res., 101, 9471-9478, 1996. 
Neu, J. L., Sparling, L. C., and Plumb, R. A.: Variability of the subtropical "edges" in the stratosphere, J. Geophys. Res., 108, 4482, doi:10.1029/2002JD002706, 2003.

O'Sullivan, D. and Dunkerton, T. J: The influence of the quasibiennial oscillation on global constituent distributions, J. Geophys. Res., 102, 21731-21743, 1997.

Palazzi, E. and Fierli, F.: Diagnostics of mixing and transport in the atmospheric interfaces: the project DIMITRI, Proceedings of the ESA Living Planet Symposium, Bergen, Norway, 28 June-2 July 2010, ESA SP-686, 2010.

Patra, P. K., Lal, S., Venkataramani, S., and Chand, D.: Halogen Occultation Experiment (HALOE) and balloon-borne in situ measurements of methane in stratosphere and their relation to the quasi-biennial oscillation (QBO), Atmos. Chem. Phys., 3, 10511062, doi:10.5194/acp-3-1051-2003, 2003.

Pierrehumbert, T. and Yang, H.: Global chaotic mixing on isentropic surfaces, J. Atmos. Sci., 50, 2462-2480, 1993.

Plumb, R. A.: Stratospheric transport, J. Meteorol. Soc. Jpn., 80, 793-809, 2002.

Plumb, R. and Ko, M.: Interrelationships between mixing ratios of long-lived stratospheric constituents, J. Geophys. Res., 97, 10145-10156, 1992.

Polvani, L. M., Waugh, D. W., and Plumb, R. A.: On the subtropical edge of the stratospheric surf zone, J. Atmos. Sci., 52, 12881309, 1995.

Randel, W. J., Wu, F., Russell, J. M., Roche, A., and Waters, J. W.: Seasonal cycles and QBO variations in stratospheric $\mathrm{CH}_{4}$ and $\mathrm{H}_{2} \mathrm{O}$ Observed in UARS HALOE Data, J. Atmos. Sci., 55, 163185, 1998.

Russell III, J. M., Gordley, L. L., Park, J. H., Drayson, S. R., Hesketh, W. D., Cicerone, R. J., Tuck, A. F., Frederick, J. E., Harries, J. E., and Crutzen, P. J.: The Halogen Occultation Experiment, J. Geophys. Res., 98, 10777-10797, 1993.

Schoeberl, M. R., Douglass, A. R., Newman, P. A., Lait, L. R., Lary, D., Waters, J., Livesey, N., Froidevaux, L., Lambert, A., Read, W., Filipiak, M. J., and Pumphrey, H. C.: QBO and annual cycle variations in tropical lower stratosphere trace gases from HALOE and Aura MLS observations, J. Geophys. Res., 113, D05301, doi:10.1029/2007JD008678, 2008.

Shuckburgh, E., Norton, W., Iwi, A., and Haynes, P.: The influence of the quasi-bienniel oscillation on isentropic transport and mixing in the tropics and subtropics, J. Geophys. Res., 106, 1432714338, 2001.

Shuckburgh, E., d'Ovidio, F., and Legras, B.: Local Mixing Events in the Upper Troposphere and Lower Stratosphere, Part II: Seasonal and Interannual Variability, J. Atmos. Sci., 66, 3695-3706, 2009.

SPARC CCMVal: SPARC CCMVal Report on the Evaluation of Chemistry-Climate Models, edited by: Eyring, V., Shepherd, T. G., and Waugh, D. W., SPARC Report No. 5, WCRP-X, WMO/TD-No. 1526, available at: http://www.atmosp.physics. utoronto.ca/SPARC, 2010.

Sparling, L. C.: Statistical perspectives on stratospheric transport, Rev. Geophys., 38, 417-436, 2000.

Strahan, S. E. and Douglass, A. R.: Evaluating the credibility of transport processes in simulations of ozone recovery using the Global Modeling Initiative three-dimensional model, J. Geophys. Res., 109, D05110, doi:10.1029/2003JD004238, 2004.

Strong, K., Wolff, M. A., Kerzenmacher, T. E., Walker, K. A.,
Bernath, P. F., Blumenstock, T., Boone, C., Catoire, V., Coffey, M., De Mazière, M., Demoulin, P., Duchatelet, P., Dupuy, E., Hannigan, J., Höpfner, M., Glatthor, N., Griffith, D. W. T., Jin, J. J., Jones, N., Jucks, K., Kuellmann, H., Kuttippurath, J., Lambert, A., Mahieu, E., McConnell, J. C., Mellqvist, J., Mikuteit, S., Murtagh, D. P., Notholt, J., Piccolo, C., Raspollini, P., Ridolfi, M., Robert, C., Schneider, M., Schrems, O., Semeniuk, K., Senten, C., Stiller, G. P., Strandberg, A., Taylor, J., Tétard, C., Toohey, M., Urban, J., Warneke, T., and Wood, S.: Validation of ACEFTS $\mathrm{N}_{2} \mathrm{O}$ measurements, Atmos. Chem. Phys., 8, 4759-4786, doi:10.5194/acp-8-4759-2008, 2008.

Struthers, H., Bodeker, G. E., Austin, J., Bekki, S., Cionni, I., Dameris, M., Giorgetta, M. A., Grewe, V., Lefvre, F., Lott, F., Manzini, E., Peter, T., Rozanov, E., and Schraner, M.: The simulation of the Antarctic ozone hole by chemistry-climate models, Atmos. Chem. Phys., 9, 6363-6376, doi:10.5194/acp-9-63632009, 2009.

Trepte, C. R. and Hitchman, M. H.: Tropical stratospheric circulation deduced from satellite aerosol data, Nature, 355, 626-628, 1992.

Trepte, C. R., Veiga, R. E., and McCormick, M. P.: The poleward dispersal of Mount Pinatubo volcanic aerosol, J. Geophys. Res., 98, 18563-18573, 1993.

Urban, J., Lautié, N., Le Flochmoën, E., Jimenez, C., Eriksson, P., de la Noë, J., Dupuy, E., El Amraoui, L., Frisk, U., Jegou, U. F., Murtagh, D., Olberg, M., Ricaud, P., CamyPeyret, C., Payan, S., Dufour, G., Huret, N., Pirre, M., Robinson, A. D., Harris, N. R. D., Bremer, H., Kleinbohl, A., Kullmann, K., Kunzi, K., Kuttipurath, J., Ejiri, M., Nakajima, H., Sasano, H. Y., Sugita, T., Yokota, T., Piccolo, C., Raspollini, P., and Ridolfi, M.: Odin/SMR limb observations of stratospheric trace gases: validation of $\mathrm{N}_{2} \mathrm{O}$, J. Geophys. Res., 110, D09301, doi:10.1029/2004JD005394, 2005.

von Clarmann, T., Höpfner, M., Kellmann, S., Linden, A., Chauhan, S., Funke, B., Grabowski, U., Glatthor, N., Kiefer, M., Schieferdecker, T., Stiller, G. P., and Versick, S.: Retrieval of temperature, $\mathrm{H}_{2} \mathrm{O}, \mathrm{O}_{3}, \mathrm{HNO}_{3}, \mathrm{CH}_{4}, \mathrm{~N}_{2} \mathrm{O}, \mathrm{ClONO}_{2}$ and $\mathrm{ClO}$ from MIPAS reduced resolution nominal mode limb emission measurements, Atmos. Meas. Tech., 2, 159-175, doi:10.5194/amt-2-159-2009, 2009.

von Clarmann, T., De Clercq, C., Ridolfi, M., Höpfner, M., and Lambert, J.-C.: The horizontal resolution of MIPAS, Atmos. Meas. Tech., 2, 47-54, doi:10.5194/amt-2-47-2009, 2009b.

Waters, J. W., Froidevaux, L., Harwood, R. S., Jarnot, R. F., Pickett, H. M., Read, W. G., Siegel, P. H., Cofield, R. E., Filipiak, M. J., Flower, D. A., Holden, J. R., Lau, G. K. K., Livesey, N. J., Manney, G. L., Pumphrey, H. C., Santee, M. L., Wu, D. L., Cuddy, D. T., Lay, R. R., Loo, M. S., Perun, V. S., Schwartz, M. J., Stek, P. C., Thurstans, R. P., Boyles, M. A., Chandra, K. M., Chavez, M. C., Chen, G. S., Chudasama, B. V., Dodge, R., Fuller, R. A., Girard, M. A., Jiang, J. H., Jiang, Y. B., Knosp, B. W., LaBelle, R. C., Lam, J. C., Lee, K. A., Miller, D., Oswald, J. E., Patel, N. C., Pukala, D. M., Quintero, O., Scaff, D. M., Van Snyder, W., Tope, M. C., Wagner, P. A., and Walch, M. J.: The Earth Observing System Microwave Limb Sounder (EOS MLS) on the Aura satellite, IEEE T. Geosci. Remote, 44, 1075-1092, 2006. 